\title{
EL ORGANERO NOVOHISPANO MANUEL JOSÉ CHACÓN Y EL ÓRGANO PARROQUIAL DE LA VILLA DE ATLIXCO, (PUEBLA, MÉXICO)
}

\author{
Gustavo Mauleón Rodríguez \\ Benemérita Universidad Autónoma de Puebla (México)
}

\section{Resumen:}

En este artículo se dan a conocer de manera más amplia y a nivel internacional algunas facetas de la actividad de una de las familias más notables de organeros novohispanos, cuyo taller floreció principalmente en la ciudad y obispado de la Puebla de los Ángeles durante el siglo XVIII. Se contribuye particularmente con nuevas noticias sobre uno de sus miembros: el organero, teórico y "profesor de música instrumental" Manuel José Chacón, también vinculado a la catedral de Puebla como afinador de los órganos; asimismo, se aportan pruebas documentales sobre la construcción del órgano del curato de la Villa de Atlixco — cercana a la ciudad de Puebla-, cuya autoría se había considerado hasta ahora como anónima. Este instrumento sin duda constituye un ejemplo sobresaliente de la organería novohispana, especialmente en los aspectos de diseño y construcción de órganos "de segunda especie".

\section{Palabras clave:}

Nueva España, Atlixco, Puebla (México), siglo xvIII, órgano, organería, Manuel José Chacón.

\begin{abstract}
In this article are reported some of the facets of the activities of one of the most notable vice- regal organ-builders family, which workshop was developed principally in the city and bishopship of Puebla de los Angeles on the 18th century. Contributing particularly with new facts of one of its members: the organ-builder, treatise and "Profesor de música instrumental", Manuel José Chacón, who is as well related to the Puebla Cathedral as Organ maintainer; on the other hand we are contributing with documental research of the construction of the Villa de Atlixco parish's organ — near to Puebla city — which author was considered as anonymous until now. This instrument gives an extraordinary example of vice-regal organ-building, specifically in design and "segunda especie" organ-building.
\end{abstract}

Key Words:

New Spain, Atlixco, Puebla (México), 18th century, organ, organ-building, Manuel José Chacón. 


\section{ANTECEDENTES DE UNA CAPILla MUSiCAL}

El martes 21 de junio de 1644, durante su segunda visita eclesiástica "en los lugares del obispado que miran a cercanía de la Puebla", el obispo don Juan de Palafox y Mendoza, que venía procedente de Cholula, llegó a las afueras de "Atrizco", donde fue recibido por la villa entera y su alcalde mayor don Nuño de Villavicencio. A su arribo el prelado dio la bendición solemne a todo el pueblo en la iglesia parroquial y descansó durante unas horas en la casa del licenciado Sancho de Llanos que era uno de los padres beneficiados de dicho partido ${ }^{1}$. Por la tarde, al continuar su larga jornada, realizó también confirmaciones y en los siguientes días prosiguió con las actividades pastorales y sacramentales de su visita episcopal, de la cual el propio don Juan anotaba:

"Al día siguiente, que fue miércoles, prediqué al pueblo para disponerles a la visita. El jueves confirmé y el viernes, día de San Juan Bautista, por la mañana, asistí a la misa mayor porque en esta parroquia se hacen los oficios con grande solemnidad. A la mañana del sábado hice confirmaciones y confesé, y el otro siguiente domingo hice la visita, volví a predicar y comulgaron muchos del pueblo. En esta villa consagré dos campanas, una de la parroquia y otra del convento de San Francisco. Visité el hospital y la capilla y ermita de San Félix. Di algunas órdenes, señaladamente en materia de culto divino y aumento de la capilla y música de la parroquia. Visité también la parroquia de indios de San Francisco: porque ésta sólo se sujetó [a la autoridad del obispado a partir de 1641$]^{2}$. Dile orden al doctrinero que es el padre fray Gabriel Arias, que comprase relicario para llevar el Santísimo, porque no trajese [a] los enfermos a la puerta de las visitas del partido. Vi también a las religiosas de Santa Clara, sujetas a los frailes"3.

Nuestro obispo menciona también desde su llegada, haber platicado con los clérigos que asistían la villa, alentándolos "para que hiciesen actos de devoción y formasen los días que se habían de juntar", asimismo como le era costumbre les dejaba "algunas órdenes por donde se habían de gobernar", recomendaciones que sin duda, eran parte de su ideario pastoral en el cumplimiento del ministerio parroquial tridentino, sobre todo el que debería llevarse a cabo en las comunidades de su extenso obispado, y que, desde luego, en la medida de sus posibilidades, había llevado a la práctica, lo que

1 En la antigua Villa de Carrión (Atlixco) se administraban los sacramentos desde el siglo XVI en una parroquia secular y otra regular, de españoles e indios respectivamente. A mediados del siglo xVII, la primera de ellas, cuya advocación era la "Natividad de la Virgen" o "Nuestra Señora de la Natividad", tenía dos curas beneficiados, el vicario don Nicolás de Nava y de la Mota y el licenciado don Sancho de Llanos, había 16 clérigos que mantenían una hermandad de sacerdotes "con un altar en la misma parroquia [...] muy bien adornado". Asimismo esta parroquia tenía siete cofradías con sus diferentes devociones; había además dos obras pías para casar huérfanas que funcionaban en el convento de Nuestra Señora de la Merced y en el de San Agustín, fundadas y dotadas por los presbíteros Antonio Núñez de Guzmán y Antonio de Macías respectivamente. Véase PALAfox y Mendoza, Juan de: Relación de la visita eclesiástica del obispo de Puebla (1643-1646). (Transcripción, introducción y notas de Bernardo García Martínez). Puebla, Secretaría de Cultura, 1997, pp. 59 y 60.

2 Íbid., p. 60, n. 7. Ver también OBREGón, Gonzalo: Atlixco la ciudad y sus monumentos. México, inAh, 1981 , pp. 80 y 81.

3 Palafox y Mendoza, Juan de: op. cit., pp. 60 y 61. 
también implicaba su constante verificación y vigilancia a través de una continua comunicación con sus párrocos. Prueba de ello la encontramos sólo dos años después en un edicto publicado en 1646 acerca de los ornamentos, vasos sagrados, alhajas e instrumentos que consideraba eran necesarios en las parroquias y, en general, para el "lucimiento del culto divino"4, documento en el que, entre otros tantos asuntos, solicitaba también que le fuese informado por parte de los prefectos de las "cordilleras" sobre las alhajas que desde la segunda visita habían aumentado en las de Tlaxcala, Cholula, Atlixco, Tepeaca, Tehuacán y Orizaba.

Cabe destacar que en la relación de su vista a Atlixco, Palafox menciona haber consagrado dos campanas, asunto sobre el que abundará en su posterior edicto de 1646, documento en el que recomienda que haya "un campanario para las campanas, que esté cubierto y con algún género de adorno, como torrecilla u otro desta calidad. Y tengan por lo menos tres campanas las mayores que se puedan". De igual manera pone un especial énfasis en dictar disposiciones "en materia de culto divino y aumento de la capilla y música de la parroquia", lo que significaba, según el citado edicto, que la iglesia parroquial debería tener, conservar y en su caso aumentar determinados libros litúrgicos e instrumentos de música, a saber: Misales (un par y de no ser posible, por lo menos uno para el coro), Breviario, Psalterio, Dominical, Ferial, Cuaresmal, de difuntos, común de festividades comunes, así como de festividades solemnes (este último libro por lo menos duplicado). En cuanto a los instrumentos musicales recomienda que "Procuren conservar mucho los instrumentos de canto, de que hay tanta copia en las parroquias destas provincias, y el principal de ellos es el órgano. Y que vayan aprendiendo los indios porque nunca les falte quien lo sepa tocar", a continuación el obispo daba una lista de los instrumentos que había aprobado para las funciones litúrgicas, advirtiendo que si no les era posible tener un par de cada uno, por lo menos hubiese uno sólo de cada familia: órgano (del cual "se procure mucho que no haya parroquia sin él"), arpa, un juego flautillas (puede referirse a una familia completa de flautas dulces o por lo menos a dos altos, que eran las más comúnmente utilizadas), un juego de chirimías, bajón, corneta, y un juego de trompetas (de éstas últimas, sin embargo, aclara que se deberán usar solamente fuera del templo "a sus puertas, antes y después de la misa y de los oficios divinos"). En lo que hace al papel de los instrumentos utilizados especialmente para la misa, agrega de manera contundente: "Y adviertan que al tiempo que se dice la misa mayor, cuando no se canta alguna chanzoneta, particularmente después de ser alzado el Señor, han de usar de los instrumentos más suaves y que perturben menos, como son el órgano, arpa y flautillas, porque antes despierten atención al misterio, que ruido [y] perturbación; y [que] las trompetas nunca se tañan dentro de la iglesia"'s.

4 Edictos del ilustrísimo y reverendísimo señor don Juan de Palafox y Mendoza, obispo de la Puebla de los Ángeles [...] de los ornamentos y vasos sagrados y las demás alhajas y instrumentos que son necesarios para las parroquias y lucimiento del culto divino, Puebla, Juan Blanco de Alcázar, 1646, ff. 1r-19r. (Biblioteca "Palafoxiana" de Puebla). Cfr., FERnÁNDEz Gracia, Ricardo: Don Juan de Palafox teoría y promoción de las artes. Pamplona, Asociación de Amigos del Monasterio de Fitero, 2000, pp. 340-342.

5 Íbid., ff. 17r-18r; y p. 151. 
Con relación a la parroquias e iglesias de Atlixco, las observaciones sobre los asuntos musicales que el obispo Palafox hiciera y anotara durante su visita a la villa en 1644, y las disposiciones de sus edictos posteriores que hemos comentado, evidentemente fueron cumplidas y llevadas a la práctica, hechos que podemos corroborar también en otros escritos palafoxianos, uno de ellos de suma importancia es el conocido como De la naturaleza del indio, opúsculo que tuvo su primera edición en torno a 1650, a su regreso a España, y al parecer durante la breve estancia de este personaje en Madrid —en el Consejo de Aragón-, en el capítulo 16 de dicha obra titulado "De la industria del indio, señaladamente en la artes mecánicas" Palafox escribió:

"A Atrisco una de las villas del obispado de la Puebla de los Ángeles, llegaron un español y un indio a aprender música de canto de órgano con el maestro de capilla de aquella parroquia, y el español que en más de dos meses no pudo cantar la música de un papel, ni entenderla, y el indio en menos de quince días le cantaba diestramente. Hay entre ellos [los indios de Atlixco] muy diestros músicos, aunque no tienen muy buenas voces; y los instrumentos de harpa, chirimías, cornetas, vajones, y sacabuches, los tocan muy bien, y tienen libros de música en sus capillas, y sus maestros de ella en todas las parroquias, cosa que comúnmente sólo se halla en Europa en las [iglesias] catedrales, o colegiales"6.

En efecto, no sólo la parroquia principal de la villa llegó a contar con una capilla musical de importancia, sino que en la región se desarrollaron también otras capillas de músicos y cantores verdaderamente notables, a las que Palafox hace clara referencia; sin duda el más antiguo antecedente de ellas, es la que funcionaba en la comunidad de Acapetlahuacan desde el siglo XVI, en el establecimiento franciscano de Santa María de Jesús — cuyos frailes reconocieron y se sujetaron a la autoridad episcopal, (1641-1755), continuando con la administración de su doctrina más allá de la época de la secularización palafoxiana— ${ }^{7}$, esta célebre cantoría o capilla musical indígena tenía bienes propios y se beneficiaba

6 Palafox y Mendoza, Juan de: "De la naturaleza del indio...", en Obras del Ilustríssimo, Excelentísimo y Venerable Siervo de Dios... Madrid, Imprenta de don Gabriel Ramírez, 1762, t. x, $\S .3^{\circ}$. El párrafo segundo del mismo capítulo, nos puede mostrar también, a través de sus observaciones, el especial interés que el obispo Palafox tenía en los órganos como instrumento eclesiástico: "A México vino un indio de nación tarasco, [...] a aprender a hacer órganos, y llegó al artífice y le dijo que le enseñase, y se lo pagaría, el español quiso hacer escritura de lo que había de darle, y por algún accidente dejó de hacerla seis días, teniendo entre tanto en casa al indio. En este tiempo compuso el maestro un órgano que tenía hechas las flautas, y sólo cosa de verlas el indio poner, y disponer, y tocar, y todo lo que mira al interior artificio de este instrumento; viniendo a hacer la escritura, dijo el indio que ya no había menester que le enseñase, que ya sabía hacer órganos, y se fue a su tierra, e hizo uno con las flautas de madera, y con tan excelentes voces, que ha sido de los raros que ha habido en aquella provincia, y luego hizo otros estremados [sic] de diferentes metales, y fue eminente en su oficio". (Para todas las fuentes impresas y manuscritas hemos hecho una trascripción literal modernizada).

Véase una interesante visión de conjunto sobre diversos aspectos musicales relacionados con don Juan de Palafox en Gembero Ustárroz, María: "El mecenazgo musical de Juan de Palafox (1600-1659), Obispo de Puebla de Los Ángeles y Virrey de Nueva España", en Palafox. Iglesia, Cultura y Estado en el siglo XVII, (Fernández Gracia, Ricardo, coord.). Pamplona, Universidad de Navarra, 2001, pp. 463-496.

7 Sobre la solicitud de restitución de algunos conventos a la provincia franciscana del Santo Evangelio en 1765, entre los que se encontraba la "Visitación de la villa de Atlixco", véase MAzín Gómez, Óscar: "Reorganización del clero secular novohispano en la segunda mitad del siglo xvIII", en Relaciones, núm. 39, verano 1989, vol. x, p. 76, n. 19. 
de sus rentas, lo que permitía el sostenimiento de un nutrido grupo de cantores, ministriles y organistas a cargo de un maestro de capilla ${ }^{8}$.

Cabe comentar que en 1659 el licenciado Nicolás Griñón, "que tiene muy buena voz y es diestro en los instrumentos de arpa y violón y muy buen compossitor", se desempeñaba como "Maestro en Artisco"; y desde finales del siglo xviI, el maestro de capilla y organista de la parroquia de La Natividad era el músico Andrés de Santa María originario de Puebla y vecino de la villa, quien se había educado en la catedral angelopolitana, y había sido ayudante de organista durante dos años. Este músico solicitó entre octubre y noviembre de 1703, por muerte del organista Francisco Vidales, hacer examen de oposición a la plaza de organista mayor de dicha catedral, a principios de diciembre de ese año se presentó junto con los organistas Luís de Bomborán y Francisco Manuel de Carabantes, no resultando favorecido con dicho puesto. Cabe mencionar que entre los examinadores se encontraba el maestro de capilla Miguel Mateo Dallo y Lana, el ministril de arpa Gregorio Rodríguez y el rector del colegio de infantes Miguel de Riva Pastor". Podemos anotar también que el bachiller Bernardino Domínguez "clérigo, presbítero domiciliario de este obispado", era "natural de la Villa de Carrión, Valle de Atrizco" —y persona muy cercana al organista Francisco Vidales-, en esta época se desempeñaba como sochantre, capellán, cantor y maestro de canto llano en la catedral de Puebla, habiéndose formado muy probablemente en la capilla musical de la parroquia Atlixquense. Asimismo, sabemos que en 1788 aún ejercía como sochantre y maestro de capilla de dicha parroquia el ministro Antonio José Gálvez y Morón ${ }^{10}$.

Con base en estos antecedentes podemos considerar que el órgano o los órganos que poseía al menos la parroquia principal de Atlixco, eran con seguridad instrumentos de muy buena factura, dadas las necesidades de una capilla musical debidamente constituida dedicada a una intensa actividad litúrgica y paralitúrgica, las características arquitectónicas de la iglesia, cuyas dimensiones en el siglo XVII al parecer eran semejantes a las actuales ${ }^{11}$, y desde luego, atendiendo y obedeciendo las

8 Archivo General de Notarías del Estado de Puebla (agneP), Notaría 4, Escribano Juan de Bedoya, caja núm. 4, Protocolos del año 1568, ff. 197r-198v; y Notaría de Atlixco, Protocolos del año 1601, ff. 189r-189v.

9 Una referencia sobre la actividad en Atlixco de Nicolás Griñón (cantor y ministril de arpa y violón en la catedral de Puebla de 1643 a 1651 y de 1652 a 1667), véase en Francisco J. Rodríguez-Erdmann, Maestros de Capilla vallisoletanos: Estudio sobre la capilla musical de la catedral de Valladolid-Morelia en los años del virreinato, Morelia, Ed. del autor, 2007, pp. 120121. Sobre la oposición de Andrés de Santa María ver: Archivo del Cabildo de la Catedral de Puebla (ACCP), Leg. Documentos y decretos sobre empleados del coro 1648-1859, expediente s.a. [suscrito entre octubre y noviembre de 1703], f. [44]r; AC, L. 21 (1703-1711), ff. 38r y 40r (acuerdos de cabildo del 4 y 8 de diciembre de 1703). Véase también Stevenson, Robert: Christmas music from barroque Mexico. Los Angeles, University of California Press, 1974, p. 73; ID.: "Puebla Chapelmasters and Organists: sixteenth and seventeenth centuries, part II", en Inter-American Music Review, vol. vi, núm. I, (otoño de 1984), p. 119.

10 Bernardino Domínguez otorgó su testamento ante escribano público el 15 de julio de 1701 y murió el 15 de octubre de 1706; fue sepultado en la capilla del Señor de la Columna en la catedral de Puebla —ya que ésta era la capilla de devoción de los músicos y cantores, quienes desde 1688 tenían licencia para su culto y en ella se podían enterrar sin dar limosna, asimismo su cuidado se confería al maestro de capilla. Véase AGNEP, Notaría núm. 5, escribano Manuel Payán, Protocolos testamentarios de 1701, f. s.n.; Archivo del Sagrario Metropolitano de Puebla (ASMP), Libro de defunciones de españoles núm. 5 (1699-1708), f. 154v; ACCP, "Libro en que se asientan las limosnas de sepulturas de esta santa iglesia catedral desde veinte y uno de julio de mil setecientos y noventa y cuatro años", f. 56v. Un poder para testar de Antonio José Gálvez y Morón se localiza en AGNEP, Notaría 3, Escribano Manuel del Castillo, Protocolos de 1786-1788, f. 5r.

11 Obregón, Gonzalo: op. cit., pp. 111 y 112; Cfr. también DíAz, Marco: Arquitectura religiosa en Atlixco. México, IIE/ UNAM, 1974, p. 51. Algunos años después este estudio fue reeditado íntegro con alguna adición documental bajo el nuevo título de Antigua Villa de Carrión, arquitectura religiosa y civil. Puebla, INAH, 1987. 
recomendaciones tan específicas, dadas en su momento por el obispo. En cuanto a los constructores de esos instrumentos no tenemos noticias, sin embargo, hay que considerar que en el contexto local en Puebla, y a nivel regional sobre todo en la parte central del obispado, trabajaron principalmente los organeros Diego Sebaldos al mediar el siglo XVII, posteriormente estuvieron activos también los organeros Miguel Ordóñez y Melchor Rodríguez, este último, padre de Bernardo y Joseph Rodríguez, quienes serían importantes constructores y afinadores vinculados a la catedral de Puebla ya en el siglo XVIII. En esa misma centuria y hasta principios del siglo XIX tendrá un lugar muy destacado dentro del panorama de la organería poblana, otro notable taller familiar de constructores, restauradores y afinadores, iniciado por José Miguel Chacón Riviera, y continuado por su hijo Manuel José Chacón Duarte y Dávila y su nieto José Antonio Chacón Rojano.

Para ese entonces la parroquia de La Natividad de Atlixco estaba siendo reconstruida debido a un terremoto que en 1768 derribó la torre sobre parte de la nave del templo, justo al momento de una misa, lo que había causado muchas muertes. Estos hechos, otros detalles diversos sobre el funcionamiento litúrgico y administrativo de la parroquia, así como una breve descripción de la iglesia y el curato, nos la da don Ignacio Maneyro en una relación de 1792:

"En el culto divino, se acreditan los piadosos esmeros de este vecindario, pues su parroquia, que fue casi arruinada por el año de 1768, a la violencia de un terrible terremoto, acostándosele su elevada torre encima, se halla a la presente reparada, que sin riesgo de equivocarse, se debe graduar por la mejor del obispado de la Puebla, pues está asistida de un magnífico adorno, sin echar menos los rasgos de una catedral en el ceremonial de sus serias funciones, manteniendo entre otras grandezas, su capilla [musical] con las formalidades de maestro, voces y orquesta de diestros músicos, que con buenos instrumentos concurren todos en traje eclesiástico, siendo su órgano de los más sobresalientes, que puede haber en la finura de sus mixturas.

Los curas de esta parroquia, que conocen por la [de] españoles, son dos [como lo eran en el siglo XVII] y el más antiguo goza la distinción de vicario y juez eclesiástico, y compartiendo ambos sus desvelos con igualdad, lo es también la distribución en el producto de sus emolumentos, siendo acreedores por gracia particular a los diezmos de su jurisdicción, verificando el prorrateo en esta forma: de cada veinte cargas de semillas, o frutos, las trece corresponden a la masa común de la catedral e la Puebla, y las siete restantes, las subdividen en novenos imaginarios: cuatro partes de las siete, por mitad a dichos curas, una y media para la fábrica, con lo que se atiende al consumo de cera, situados de músicos y demás utensilios de la iglesia; y el uno y medio restante, fue aplicado por su majestad al hospital real de esta villa.

Del cuadrante, o producto del curato, su octava parte se consigna de gratificación a un presbítero, que con título de sacristán mayor aprobado por superior gobierno, tiene a su cuidado el aseo de la iglesia, y es responsable de alhajas, que las tiene muy ricas en vasos sagrados y ornamentos, y una suntuosa [f. 2r] lámpara y arañas de plata, que la piedad y cristianos sentimientos del licenciado don José Garfias, presbítero avecindado en esta villa y abogado de la real audiencia con otros 
costosos adornos dignos de su bizarría, ha cedido en obsequio y gratitud de la religión que abrazó en su pila bautismal.

Hay también cura de indios, que por estar situada su iglesia en paraje más elevado que la villa, lo distinguen por el curato de arriba en el pueblo de Acapetlahuacan, que está a continuación de Atlixco, los más naturales se reconocen por feligreses de esta parroquia, como todos los de razón lo son de la principal, aunque como hay muchos, viven entre ellos, y estos por el contrario residen en la villa, la que no tiene pueblo de indios, como el curato de arriba que administra varios de esta clase" $" 12$.

Dentro del contexto de nuestro estudio podemos destacar en este texto histórico, el fastuoso ceremonial que se observaba en esta iglesia, siendo comparado inclusive con el de una catedral, menciona "entre otras grandezas" a su capilla musical, de la cual elogia a sus "diestros músicos que con buenos instrumentos" asistían a las celebraciones "en traje eclesiástico", más adelante acerca de la capilla musical aporta también el monto del pago de los músicos dentro de los gastos de la fábrica espiritual de la parroquia como era el uso administrativo. Asimismo al finalizar el primer párrafo, Maneyro nos daba la primera alusión de que tengamos noticia, sobre el gran órgano parroquial de la iglesia de La Natividad como uno "de los más sobresalientes, que puede haber en la finura de sus mixturas", de este instrumento hoy sabemos gracias a un documento protocolar hallado en el archivo de notarías de Puebla, que su autor es el organero Manuel José Chacón Duarte y Dávila, artífice que iniciaría su construcción en el año de 1789.

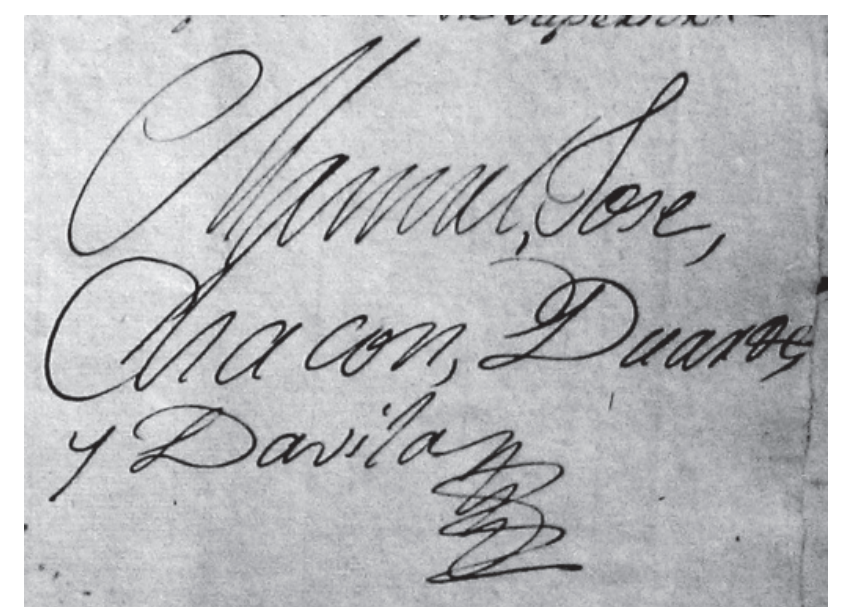

Fig. 1. Rúbrica del organero Manuel José Chacón Duarte y Dávila.

12 Maneyro, Ignacio: Relaciones Geográficas de 1792. (Estudio introductorio, transcripción y notas de RoMERO NAVARRETE, Lourdes M. y Echenique March, Felipe I.). México, inah (Colección Científica 295), 1994, pp. 120-129. 


\section{UNA FAMILIA DE ORGANEROS}

Sobre la familia Chacón y su taller podemos mencionar que tal vez los primeros datos históricos sobre su trabajo los había anotado — sin ser publicados en su momento, desde luego- el cronista don Mariano Fernández de Echeverría y Veytia en su Historia de la fundación de la ciudad de la Puebla de los Ángeles... en 1780, obra en la que, al abordar la historia de la iglesia y convento de San Agustín de dicha ciudad, entre otros datos, escribió:

"Debajo de las dos últimas bóvedas del lado de la puerta que forman el coro, sobre dos inferiores de iguales tamaños, siguen unidas a él por uno y otro lados dos tribunas hasta las pilastras de la siguiente bóveda, resguardadas ellas y el antepecho del coro de una barandilla de madera torneada, que corre uniforme de uno a otro lado. Sobre estas tribunas sentaban dos órganos, uno mayor que otro, dejando el coro enteramente desembarazado y adornado de su sillería, con bastante amplitud, y así subsistió hasta el año de 1779 en que el reverendo padre maestro fray Bernardo de Peralta quiso hacer un nuevo órgano más magnífico, y con efecto le trabajaron don José Miguel y don Manuel José Chacón, padre e hijo, de particular dibujo y estructura con cuantas diferencias, tonos, registros y secretos puede tener una pieza de éstas, de suerte que en el día no hay en la ciudad otro que le iguale. Su costo ha sido cinco mil pesos en dinero, el órgano chico que había en mil pesos y el enflautado grande, dejando sólo la capa con flautas de perspectivas para acompañar al nuevo en la tribuna del lado del la Epístola, porque el hecho ahora se colocó en el lado del Evangelio, y [ha de] computarse, que sólo a los maestros organistas se les dieron 6,200 pesos, fuera del costo de la caja que es muy primorosa, de madera de ayacahuite muy bien tallada y de los canes que se fijaron en el muro para sostenerlo, porque su gran peso no podía fiársele sólo a la tribuna, que uno y otro costó muy cerca de 400 pesos."13.

De los instrumentos mencionados desafortunadamente no se conservó ninguno, sin embargo, en tanto no conozcamos el contrato de la obra u otros documentos relacionados, los valiosos detalles que el cronista aporta, lo elogioso de sus observaciones sobre ciertos aspectos formales, las observaciones acerca de su construcción y materiales, así como los costos del nuevo órgano, resultan muy reveladores y nos hablan del tipo de instrumentos que en ese tiempo se estaban construyendo en el taller de los maestros Chacón en Puebla ${ }^{14}$.

13 Fernández de Echeverría y Veytia, Mariano: Historia de la fundación de la ciudad de la Puebla de los Ángeles en la Nueva España, su descripción y presente estado. 1780. (Ed., prólogo y notas de CASTRo Morales, Efraín). Puebla, Altiplano, $1962 / 1963$, t. II, p. 345.

14 Sobre la destrucción lamentable del órgano de los Chacón de la iglesia conventual de San Agustín en Puebla, existen algunas noticias: "En el infausto y malhadado sitio de los franceses de 1863, que tantos males y pérdidas causó a esta ciudad, este edificio se convirtió en una ciudadela fortificada y batida por la baterías rayadas, y bombardeada el 26 de abril, sábado de Gloria; 
El primero de estos artífices, José Miguel Chacón Riviera había trabajando en la construcción y restauración de órganos en varias parroquias de la región por un largo periodo a partir de la década de 1720; posteriormente, en algunas iglesias de la ciudad en compañía de su hijo, y más tarde había venido haciendo algunos arreglos de diversa índole a los instrumentos de tecla de la catedral de Puebla ${ }^{15}$, donde finalmente fue admitido y nombrado "en propiedad en la plaza de afinador" de los órganos durante el cabildo extraordinario celebrado el 29 de mayo de 1776, ya que los miembros del cabildo — con la opinión del maestro de capilla y organista- consideraron "que atendiendo a estar examinado en otra ocasión y probada su idoneidad con la compostura que ha hecho a la presente del órgano, y clave sin que volviese a nuevo examen, se nombró en propiedad en la mencionada plaza de afinador, despachándosele su título como es costumbre"16, cuyo decreto fue otorgado de manera oficial un día después, el 30 de mayo ${ }^{17}$, en este documento se le asignaba el salario que habían "gozado sus antecesores" que era de 300 pesos anuales, con la salvedad de que las composturas eventuales que necesitaran los instrumentos no deberían superar el costo de $10 \operatorname{pesos}^{18}$. El maestro Chacón trabajó para la catedral por un periodo de 12 años, hasta su muerte ocurrida el 16 de diciembre de $1788^{19}$.

Para el mes de febrero del año siguiente, hallándose vacante la plaza de afinador en la catedral, su hijo Manuel José dirigió al cabildo (reunido el 6 de febrero de 1789), un memorial20 “[...] en

fue incendiada la iglesia ya por las granadas que constantemente le dirigían, o ya porque los sitiados lo hicieran, como se dijo (a lo que damos poco crédito), el resultado fue que en pocas horas un voraz fuego, que despedía espesas columnas de humo por las ventanas, convirtió en cenizas el ornato de la nueva iglesia, un órgano célebre por su construcción, tamaño y armoniosas voces, e innumerables objetos artísticos, que habían sido reunidos en el transcurso de tres siglos y que eran una verdadera riqueza artística y pecuniaria", en Olivares IrIarte, Bernardo: Album Artístico 1874. (Ed., estudio preliminar y notas de Castro Morales, Efraín). Puebla, Gob. del Estado, 1987, pp. 15 y 16, n. 32.

15 ACCP, AC., L. 43 (1775-1778), f. 107r., (Cabildo del 24 de mayo de 1776); Íbid., L. 43, f. 107v-108v, (Cabildo extraordinario del 29 de mayo de 1776). En esta época, entre otras fuentes, los inventarios de la catedral dan cuenta de un claviórgano que sabemos era utilizado con fines didácticos, para ensayos de la capilla musical y cantores, y para uso ocasional en las capillas de la catedral, supliendo de cierta manera a los órganos que estaban en las tribunas del coro: "Un clabeórgano, y arriba tres órganos, uno grande, uno mediano y el otro chico", asimismo sabemos que en 1776 había "un clabesímbano que tiene el organista licenciado José [Gómez] Gordillo en dos piezas con el clabeórgano", una de esas piezas se guardaba en la Capilla de San Nicolás (posteriormente de San Juan Nepomuceno), ya que ésta tenía un acceso — que aún existe- a otras dependencias relacionadas con la actividad musical como la Librería de Coro y la Escoleta, además de ser la capilla más cercana a la entrada del coro y sus tribunas desde la nave de la Epístola. Véase ACCP, Inventario de Sacristía, año de 1771, f. 42v; Inventario de Sacristía, desde 1771 hasta 1776, f. 41r; Inventario de sacristía, año de 1776 , ff. 48v y 87r.

16 Ibíd., L. 43, ff. 107v-108r, (Cabildo extraordinario del 29 de mayo de 1776).

17 ACCP, Música, Leg. de órganos [1660-1805], exp. del 30 de mayo de 1776, f. s.n., (este atado de documentos perteneciente al archivo del cabildo catedralicio de Puebla, formó parte de una serie más grande de expedientes de Correspondencia de Cabildo; en 2004 fue cambiado de lugar y actualmente se localiza en uno de los estantes de música). Véase el decreto oficial en el doc. anexo núm. 1. Un traslado de dicho decreto se asentó en el Libro núm. 2 de Decretos de cabildo [1775-1885], ff. 22v-23r.

18 ACCP, Música, Leg. de órganos [1660-1805], exp. f. s.n., nota del secretario de cabildo en que informa acerca los respectivos nombramientos de José Miguel Chacón y Manuel José Chacón como afinadores de órganos de la catedral, s.a.

19 ASMP, Defunciones de Españoles, L. 18 (1787-1790), f. 89r: “[Margen izquierdo:] Don José Chacón. [Al centro:] En la ciudad de los Ángeles a 16 de diciembre de mil setecientos ochenta y ocho años: Yo el bachiller Juan García Gallo, teniente de cura entregué en la iglesia del convento de San Agustín (para que se le diera sepultura eclesiástica) al cuerpo de don José [Miguel] Chacón, español, casado que fue con doña María Duarte, recibió los santos sacramentos y lo firmé. /Juan García Gallo. [rúbrica]"

20 ACCP, Música, Leg. de órganos [1660-1805], exp. s.n. f., febrero de 1789. Ver este memorial en el doc. anexo núm. 4. 
que pretendía el ínterin de ella, [y siendo] oído por los señores [deán y cabildo], dixeron que le declaraban y declararon el ínterin de dicha plaza con las obligaciones y emolumentos que le tocan de que se le diere el decreto correspondiente" ${ }^{21}$. Más allá del interinato atorgado, Manuel José conservó la plaza de manera titular, para entonces ya era un constructor renombrado, incluso fuera del ámbito regional, gozando así de cierta fama "en otras partes del reino"; desde algunos años atrás era considerado también —en vida de su padre, y a pesar de no contar aún con el nombramiento oficial - como afinador de los órganos de la catedral de Puebla, ya que, como él mismo lo declara, desde el ingreso de su padre en 1776, lo asistía como su ayudante ${ }^{22}$. En relación con otros datos biográficos sabemos que en 1783 casó con doña Clara Rojano, verificándose su matrimonio en la parroquia del sagrario de la catedral de Puebla ${ }^{23}$. Acerca de su desempeño profesional fuera del ámbito catedralicio, cabe mencionar que la Gaceta de México en su número 17 publicado el 12 de septiembre de 1786, nos informa que Manuel José Chacón “profesor de música instrumental” vivía en el número 24 de la calle de Cholula en Puebla — muy cerca de la iglesia y convento de San Agustíndonde también estaba ubicada la "casa de su obrador" es decir el taller familiar ${ }^{24}$. En esta gaceta se publicaron algunas noticias sobre ciertas novedades que nuestro constructor, para esas fechas, había desarrollado e introducido en la fabricación de sus órganos y otros instrumentos, tanto formal y estéticamente, como técnicamente, señalando como un factor muy importante en los diseños de sus cajas, la "extraordinaria colocación" externa e interna de las diversas familias de tubos, subrayando además, la característica de no colocar ningún tubo mudo, es decir meramente ornamental, lo que considera un defecto en los mejores órganos. Se avisa también sobre otros detalles curiosos y en cierta medida cotidianos, como la fabricación de "órganos de diversas especies y cilindros de todos tamaños, no sólo para el fin de enseñar pájaros, sino para particulares diversiones de las casas, y esto con tocatas de mucho gusto a el uso y modo de la tierra”. Es de llamar la atención en estas noticias, el tratamiento comparativo que se da a diversos registros o mixturas con determinados instrumentos musicales, así como sus timbres y otros efectos acústicos. Después de avisar que el maestro Chacón ha prometido publicar nuevas noticias para divulgar sus invenciones y promover sus instrumentos, se

21 ACCP, AC., L. 47 (1783-1789), f. 284r., (Cabildo del 6 de febrero de 1789). Existe un traslado del decreto con el nombramiento de afinador en Libro núm. 2 de Decretos de cabildo [1775-1885], ff. 190v-191r. Ver doc. anexo núm 5.

$22 C f r$., doc. anexo núm. 4

23 ASMP, Matrimonios de Españoles, L. 28 (1779-1783), f. 142r: "[Margen izquierdo:] Don Manuel Chacón Duarte, doña Maria Clara Rojano. [Al centro:] En la ciudad de los Ángeles en trece de enero de mil setecientos y ochenta y tres años, habiéndose leído las tres amonestaciones que dispone el santo Concilio de Trento en tres días festivos inter misarum solemnia, así en esta santa iglesia catedral como en la de la ciudad de México, y no habiendo resultado impedimento canónico, el licenciado don Antonio Benítez, con licencia de los señores curas, les preguntó su consentimiento a don Manuel Chacón Duarte, español, soltero, organero, natural y vecino de esta ciudad y residente que fue de la ciudad de México, hijo legítimo de don Joseph Miguel Chacón y de doña Maria Ignacia Duarte Dávila; y a doña María Clara Rojano, española, doncella, natural de la doctrina de Tesmelucan [Texmelucan], y desde pequeña vecina de esta feligresía, hija legítima de don Joachín Rojano y de doña Juana Manuela de Torises; y habiéndolo expresado mutuo los desposó por palabras de presente que hicieron verdadero y legítimo matrimonio siendo testigos el licenciado don Juan de Vargas y Juan Joseph Colín, y en dicho día recibieron las bendiciones nupciales, y en fe de ello lo firmó con el teniente de cura. /Bachiller Manuel Romero [Rúbrica]; Antonio Benítez. [Rúbrica]"

24 Actualmente Avenida Reforma 300 
anuncia de manera muy elogiosa a los lectores la posibilidad de contratar la fabricación de diferentes órganos, comentando que se pueden realizar con la implementación de algún "cierto artificio" para aumentar su sonoridad y capacidad de registros, lo que dará "un efecto tan maravilloso y extraño que ponga en admiración a los más diestros facultativos"25.

Las siguientes noticias enviadas por Chacón, fueron fechadas el 20 de octubre de 1786 en Puebla y se publicaron el 21 de noviembre del mismo año en la Gaceta de México en su número 22, en el cual nos habla de "cierto temple de órgano que inventó en Valencia el célebre Félix Falcó [...] que consiste en que todas las octavas que se comprenden en el sistema estén con igual proporción: esto es, que aunque transporten una tocata por todas las cuerdas o teclas no sólo resulten las disonancias que se advierten entre los instrumentos y órganos"26. Plantea al final de sus avisos, poner en práctica ciertos tubos que imiten a la perfección el timbre de las cuerdas del violón y del contrabajo, argumentando que en el órgano que construyó para la iglesia de San Agustín de Puebla —en 1779, obra en la que trabajó al lado de su padre según el citado testimonio de Fernández de Echeverría y Veytia — ya había probado estas innovaciones, de las que promete "que de ningún modo omitirá siempre que se le mande hacer con dichas circunstancias"27.

Como parte de su trabajo como afinador y restaurador en la catedral, el maestro organero también ideó una serie de reformas que fueron planteadas al cabildo a través de varios dictámenes que realizó a los órganos entre 1774 y 1797, y que más allá de las ideas y planteamientos vertidos en tales documentos, éstos constituyen verdaderas lecciones de organería teórica, dan muestra de la experiencia y conocimiento que el maestro tenía de la ingeniería constructiva del órgano español, así como de su gran capacidad para llevarla a la práctica. Cabe hacer mención que, entre los citados dictámenes se halla también un breve manual manuscrito para la conservación de los órganos, aunque anónimo, tenemos motivos para pensar que fue escrito también por Chacón para el uso de los organistas y afinadores, titulándolo: Acerca de órganos, reflexiones importantes y algunas notas no menos esenciales ${ }^{28}$. Asimismo un fragmento de estas "reflexiones" indica que nuestro organero

25 Gaceta de México, 12 de septiembre de 1786, t. II, núm. 17, pp. 193 y 194. Ver doc. anexo núm. 2.

26 Desde 1674 en Valencia, el científico, matemático y teórico musical Félix Falcó había diseñado también un tetracordio que permitía realizar afinaciones en los instrumentos con mayor facilidad, con él consiguió dividir con éxito la octava en 12 partes iguales (temperamento igual, acaso puesto en práctica por vez primera en España); asimismo es muy probable que el maestro de capilla Carlos Patiño usara poco después uno de estos tetracordios en la capilla real en Madrid. Véase BorDAs, Cristina; Robledo, Luis y Knighton, Tess: “Jose Zaragoza's box: science and music in Charles II's Spain”, en Early Music, vol. 26, núm. 3, (agosto 1998), pp. 397-398; SAnhuesa Fonseca, María: "Falcó de Belaochaga, Félix", en Diccionario de la música española e hispanoamericana, (CASARES Rodicio, Emilio, director y coordinador general). Madrid, SGAE, 1999-2002, vol. 4, pp. 885 y 886. Sobre el maestro de capilla Carlos Patiño ver el resumen de Siemens Hernández, Lothar: "Patiño, Carlos", en Diccionario de la música española e hispanoamericana, op. cit., vol. 8, pp. 514 y 515.

27 Gaceta de México, 21 de noviembre de 1786, t. II, núm. 22, p. 241. Ver el anexo núm. 3. Cfr. CAstro Morales, Efraín: Los órganos de la Nueva España y sus artífices. Puebla, Secretaría de Cultura, 1989, pp. 44-46. Este importante trabajo de divulgación tuvo una primera versión un tanto más abreviada que se publicó bajo el mismo título en Música y ángeles, los órganos de la catedral de México. México, Sociedad de Amigos del Centro Histórico, 1983, pp. 21-37.

28 Las cursivas son mías, el título original reza solamente Reflexiones importantes y algunas notas no menos esenciales, al que le fue agregado y superpuesto de otra mano Acerca de órganos. ACCP, Música, Leg. de órganos [1660-1805], expedientes s.n. f. Ver doc. anexo núm. 7. 
había comprobado sus resultados mediante la práctica y la experiencia ante ciertas obras teóricas "Esto no me lo han dado los libros específicamente, pero sí para probarlo traen de donde deducirlo, mis observaciones y la experiencia han sido los maestros que me ministran estas reglas" 29 , refiriéndose evidentemente a tratados de música y organería, y tal vez a otras obras de ciencia, de lo cual él mismo nos deja cierta evidencia al suscribir dichos dictámenes en calidad de "profesor de una de las facultades físico matemáticas cual es la de constructor de órganos".

Manuel José Chacón sirvió a la catedral de Puebla durante 26 años, 12 como ayudante de su padre y 14 como afinador titular. En el libro de defunciones número 22 del sagrario de la catedral el presbítero don José Antonio Palomino registró su muerte el 23 de abril de 1803, y su cuerpo —al igual que el de su padre - fue sepultado en la iglesia de San Agustín de Puebla, de donde era vecino ${ }^{30}$. En acuerdo de cabildo catedralicio del 29 de abril del mismo año, el músico don José Ignacio Haedo, quien se había educado de niño en el colegio de infantes de "Santo Domingo Mártir" de la catedral, pretendía por escrito la plaza de afinador de órganos "que vacó por muerte de don José Chacón" 31 , asimismo el heredero de la familia de organeros don José Antonio Chacón Rojano, por esos días enviaría al cabildo un memorial solicitando la plaza que sirvieron su padre y su abuelo, y en la que también había asistido, aunque de manera informal, como ayudante de afinador desde el año de $1792^{32}$, no siendo favorecido con dicho puesto, sin embargo, por ahora, estos hechos e infortunios pasarán a formar parte de otra historia.

Podemos concluir por lo pronto, que los constructores Chacón mantuvieron un taller activo durante casi cien años, varios instrumentos anónimos que se han conservado en la región de Puebla y Tlaxcala principalmente, presentan semejanzas constructivas así como diversas características tipológicas en común con los órganos que conocemos de este taller en sus diferentes épocas. Asimismo hemos podido documentar y estudiar algunos instrumentos que no se conservaron, y afortunadamente otros todavía existentes, entre los que destacan en Puebla y Tlaxcala los órganos de los siguientes recintos: museo "José Luis Bello y González"33, capilla del Beato fray Sebastián de Aparicio, parroquia de San José, parroquia de La Natividad Atlixco, parroquia de San Pedro Cholula, iglesia de Santiago Tochimizolco, iglesia de La Magdalena Tlaltelulco, parroquia de Santa Ana Chiautempan y santuario de Nuestra Señora de Ocotlán.

29 Íbid., §. 6.

30 ASMP, Defunciones de Españoles, L. 22 (1802-1807), f. 39v: “[Margen izquierdo:] Don Manuel Chacón. [Al centro:] En la ciudad de la Puebla de los Ángeles a veinte y tres de abril de 1803 años. Yo el presbítero don José Palomino, teniente de cura del sagrario de esta santa iglesia catedral, entregué en la iglesia del convento de San Agustín, para que se le diera sepultura eclesiástica al cuerpo de don Manuel [José] Chacón, español, casado con doña Clara Rojano. Recibió los santos sacramentos y lo firmé. /Vicente Palomino. [rúbrica]"

31 ACCP, AC., L. 54 (1802-1805), f. 85r, (Cabildo del 29 de abril de 1803).

32 ACCP, Música, Leg. de órganos [1660-1805], Memorial y solicitud de José Antonio Chacón Rojano para el nombramiento de la plaza de afinador, exp. s.n. f. Ver doc. anexo núm. 8.

33 El órgano del museo "José Luis Bello y Gonzáles" fue gravemente dañado al intentar trasladarlo en 1999 a otro edificio, después del sismo que afectó a la ciudad de Puebla ocurrido ese mismo año; asimismo fue desmantelado de manera discrecional y sin ningún criterio de conservación por la entonces dirección de museos de la Secretaría de Cultura de Puebla. Recientemente hemos gestionado y asesorado en la parte histórica, su restauración y reconstrucción total, a cargo del restaurador Daniel Guzmán Vargas, cuyos trabajos concluyen en 2009. Sobre los órganos localizados en Tlaxcala, véase Castellón, J. y MaUleón, Gustavo, Catálogo de órganos tubulares históricos de Txacala. México, U. Iberoamericana, 1999. 


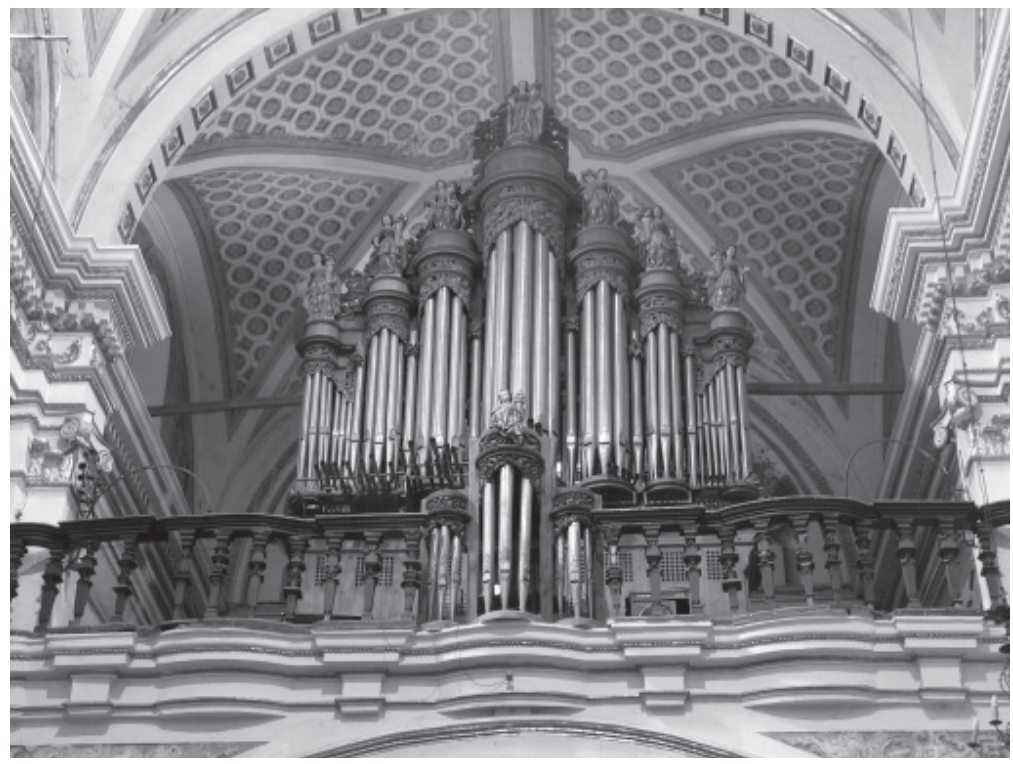

Fig. 2. Órgano de la parroquia de "La Natividad de la Virgen María" en Atlixco, Puebla (México).

\section{UN ÓRgANO DE PARROQUia}

El año de 1789 había sido muy significativo para el organero Manuel José Chacón, como hemos anotado, en el mes de febrero ingresó formalmente a la catedral de Puebla como afinador, y fue en ese mismo año que en su papel de constructor, fue contratado para la fabricación de uno de los órganos parroquiales más notables que se han conservado hasta nuestros días en México, precisamente el de la parroquia de Nuestra Señora de la Natividad de Atlixco, cuya escritura de obligación fue suscrita ante el escribano público José Jiménez Vilchis el 3 de agosto de dicho año ${ }^{34}$. A pesar de la importancia de este instrumento en el contexto de los antiguos órganos de parroquia construidos en tiempos novohispanos y aún durante el siglo XIX en la región de Puebla y Tlaxcala, no conocíamos a su autor ni la fecha de su construcción, asimismo resultaban muy escasos los acercamientos historiográficos al mismo, con sólo algunas alusiones en estudios generales de historia del arte sobre Atlixco ${ }^{35}$, un par de

34 AGNEP, Notaría de Atlixco, Escribanía de José Jiménez Vilchis, Protocolos del año de 1789, ff. 56v-58r.

35 DíAz, Marco (1974): op. cit., p. 52: "La balaustrada coral ejecutada en madera oscura está integrada por estípites y en ella se incorporan, en la parte central, las flautas del órgano. El mueble en el cual se encuentra el teclado está al centro del coro, y lo forman cinco grupos de flautas rematados por barrocas esculturas de excelente factura y gran belleza”; OBREGÓN, Gonzalo: op. cit., p. 120: "conviene señalar el magnífico órgano del coro, excepcional por sus dimensiones, por su talla y por la multitud de figuritas estofadas que lo adornan. Mencionaremos también el barandal del mismo coro, en el que cada uno de los barrotes es una pilastra estípite finamente tallada". 
registros catalográficos ${ }^{36}$, y un análisis pionero de algunos componentes del órgano. Este último fue realizado por John Fesperman, aunque muy breve, no obstante, resulta ser el primero de ellos en que se observaron ciertos detalles de importancia sobre el instrumento en cuestión:

"This organ appers to be much rebuilt; it incluyes a Cadereta case with 7 façade pipes remaining and 6 holes on each side for register knobs. The carving appears to be from a different hand than the main case; although no second keyboard now exists, there may have originally been a Cadereta division. It is possible that this case was brought from another organ. A pedalboard (with keys shaped like over-sized manual keys) exist, with 12 pull-downs from the keyboard. There is no knob adjacent to Pedal label above. The seven rounded tours suggest the builder of the Puebla Cathedral south organ, only 20 miles away" 37.

En efecto, en el instrumento que con dificultades aún funciona después de su última intervención en $1987^{38}$, se aprecian ya numerosas alteraciones, modificaciones y adiciones que podemos apreciar en la caja, los teclados, su temperamento; de la misma forma el "tono natural" o "tono de capilla" (relativamente medio tono abajo del actual diapasón) fue ajustado a La3 $=440 \mathrm{~Hz}$, algunos registros han sido alterados, los caños externos de "lengüetería tendida" de la fachada y castillos laterales se encuentran incompletos, los fuelles han sido reemplazados (tiene ahora un fuelle de depósito con ventilador eléctrico a presión aproximada de $80 \mathrm{~mm}$ ) razón por la que fueron cambiados también sus antiguos conductos o portavientos; en su interior se aprecian otras intervenciones en los secretos, en los conductos, y al parecer una buena cantidad de tubos no son originales (hemos podido verificar que algunos de estos tubos provienen de otro órgano ubicado en el coro del exconvento franciscano de Atlixco), existen faltantes, y otros tantos están dañados debido al paulatino vencimiento de sus soportes o panderetes; todo ello como parte de una problemática evidente, a la cual debemos sumar una dudosa "restauración" en 1987, así como la falta de uso y mantenimiento continuo. Fesperman observó también que lo que él denomina caja de la cadereta, aparenta ser de otra mano diferente a la de la caja principal, entiéndase de otro constructor; apunta también el número de tubos de fachada de la supuesta cadereta, así como el número de orificios de los tiradores colocados a cada lado del espacio o ventana donde antes

36 Voces del arte (inventario de órganos tubulares). México, SEdue, 1989, pp. 154-155, 422-423; GASTELlou, J. y MAULEÓN, Gustavo: Catálogo de órganos tubulares históricos del estado de Puebla. México, U. Iberoamericana, 1997, pp. 111 y 112; Véase también un breve y pionero estudio realizado a tres instrumentos de la región de Puebla y Tlaxcala por DrewES, Michael: "Órganos tubulares históricos en el área Puebla-Tlaxcala”, en Anales del Instituto de Investigaciones Estéticas, núm. 51, (1983), pp. 37-44, cuyo autor en la p. 38 comenta: "En San Martín Texmelucan y en Atlixco hallamos sendos instrumentos que en sus cajas ostentan el esplendor de la época barroca en su apogeo".

37 Fesperman, John: Organs in Mexico. Raleigh, The Sunbury Press, 1980, pp. 50-51, 76. Un compendio de este trabajo véase en ID.: "La herencia organística mexicana”, en Anales del Instituto de Investigaciones Estéticas, núm. 61, (1990), pp. 99-105, (artículo publicado originalmente en Musical Times, New York, febrero de 1984).

38 Según el inventario de órganos de 1989, el instrumento "ha sido restaurado varias veces como consta en papeles periódicos fechados en muy diferente épocas que tiene pegados en su interior. En 1987 lo restauró Ignacio Zapata Abreu, siguiendo las instrucciones de la organera Susan Tattershall" (Voces del arte, op. cit., pp. 422-423). 
hubo un teclado. Sobre este punto coincidimos en que ambas cajas tienen evidentes diferencias en sus características constructivas y estéticas, sin embargo, además de que no se menciona la fabricación de una cadereta en la escritura del nuevo órgano, pensamos que en verdad se trata del segundo cuerpo de la pequeña caja de un órgano de 6 1/2 palmos, que debió tener entre 6 y 8 registros dadas sus dimensiones, así como las proporciones de los 9 tubos - decorados con mascarones policromados, a diferencia de los caños de fachada del órgano de Chacón sin decoración- de un flautado mayor que conserva y que están dispuestos a partir de tres "castillos" de planta semicircular. Esta caja seguramente fue colocada sólo de manera ornamental para simular una cadereta ${ }^{39}$ que recordase a la de la catedral de Puebla, no obstante en muchas de las caderetas existentes en España, éstas van colocadas en órganos de tribuna lateral y generalmente en la fachada del órgano que mira hacia el interior del coro. Podemos observar también que los tubos de la fachada de esta falsa cadereta — que no son en cantidad los que debió tener originalmente - no están asentados en sus respectivos tablones acanalados y solamente se sostienen por un alambre que los sujeta a las caladuras de la ornamentación de los castillos.

Cuando se derribó la torre sobre la bóveda en 1768, ésta debió caer hacia el lado poniente de la nave y el frente de la iglesia, cuya fachada se puede observar reconstruida, asimismo el coro y en él el órgano u órganos, debieron resultar con algún daño, tal vez por ello, y por la evidente necesidad de renovar la parroquia se tuvo el interés de adquirir un nuevo instrumento. Del viejo órgano no conocemos mayores datos y sólo sabemos que fue entregado como parte del pago al constructor Chacón como era lo usual en este tipo de contratos. Fesperman repara también en lo curioso del teclado del pedal, mismo que nos parece más bien, una adaptación funcional muy posterior realizada a manera de un "teclado de contras", que en este caso tiene en su ámbito una octava cromática (Do2-Do3); al final de su comentario sugiere que por la forma y disposición del segundo cuerpo de la caja, podría tratarse del constructor del órgano de la tribuna sur de la catedral de Puebla, es decir de Félix Izaguirre ${ }^{40}$, cuyo instrumento fue conocido antiguamente como "el órgano grande" de la catedral y, sin duda, llegó a representar durante mucho tiempo un modelo formal y constructivo para los organeros locales, lo que se colige debido a ciertas características constructivas de los órganos aún existentes de Joseph Rodríguez y de los Chacón que hemos tenido la oportunidad de estudiar.

39 Cabe recordar que en su citada crónica, Fernández de Echeverría y Veytia observaba que al órgano chico que había en San Agustín, los organeros Chacón le habían puesto "sólo la capa con flautas de perspectivas para acompañar al nuevo en la tribuna del lado del la Epístola, porque el hecho ahora se colocó en el lado del Evangelio", es decir dispusieron su fachada con flautas mudas de manera ornamental para armonizarlo estéticamente con el órgano nuevo. Creemos que este puede ser el mismo caso de la cadereta ornamental o falsa cadereta de La Natividad de Atlixco, no obstante, debemos tomar en cuenta que se trata de uno de los pocos instrumentos situados al centro del coro con la fachada mirando hacia la nave del templo, ya que la gran mayoría de estos órganos parroquiales eran colocados en el coro de manera lateral y exentos, por razones funcionales y acústicas. Vid. supra nota 13 .

40 El "maestro de hacer órganos" Félix Izaguirre contrató en 1707 con el deán de la catedral de Puebla doctor Pedro de Rezábal, fabricar un órgano grande por el precio de 15,000 pesos y aderezar el órgano mediano con un costo de 1,000 pesos. El "órgano grande" fue entregado en 1710, sin embargo después de una "controversia" de varios años entre el cabildo y el constructor, y debido al mal estado y deterioro que para entonces ya presentaba el instrumento — además de haberse incrementado los costos más de 26,000 pesos- fue "aderezado" finalmente entre 1720 y 1722 por el "maestro de órganos" Bernardo Rodríguez. 
Asimismo cabe sugerir que algunos aspectos de los registros originales del órgano de Atlixco pueden estar relacionados con el órgano de Izaguirre, un caso podría ser la aplicación de ciertos registros de la familia de "Nasardos", que para esta época seguían siendo mixturas de uso frecuente, sin embargo, hemos de tomar en cuenta que de ellos tuvo una muy particular composición el órgano de la catedral de Puebla — como ya lo ha señalado Simon Platt— ${ }^{41}$, instrumento que como hemos observado en los citados dictámenes, conocían a la perfección los maestros Chacón. Con relación a las diferentes familias de tubos que componen el órgano de Atlixco, hemos comparado en un primer acercamiento, los registros de la escritura y proyecto de Chacón de 1789 con los del estudio de Fesperman de 1980 (cuadro 1), quien anota en pies la longitud de los tubos principales de cada familia y enlista los registros con la denominación que él mismo transcribió, aunque en orden diferente al de las etiquetas de los tiradores, mismas que aún se encuentran a los costados, así como en la parte superior e inferior de la ventana del teclado manual; estas etiquetas manuscritas sustituyeron a las originales y fueron colocadas después de alguna reforma importante realizada al órgano al parecer durante la segunda mitad del siglo XIX, asimismo las hemos trascrito en otro cuadro respetando su ortografía, orden y colocación real denominando a cada uno de los tiradores (cuadro 2). En un tercer cuadro hacemos una propuesta de lo que pudo haber sido la disposición original de los registros en los tableros de ambas manos —no obstante, es probable que la disposición de los tiradores haya sufrido también algunos cambios-, para tal efecto hemos tomado en cuenta para nuestro análisis general los elementos anteriores y las observaciones resultado del examen físico del instrumento (cuadro 3). La comparación de estos cuadros nos puede dar una idea aproximada de algunas modificaciones realizadas al órgano por lo menos hasta el siglo XIX, sin embargo aún hace falta un conocimiento detallado sobre otras modificaciones antiguas y los cambios y alteraciones más recientes en sus diferentes componentes, por lo que, a través de una restauración calificada, en primera instancia, tendríamos un análisis más amplio para un diagnóstico mucho más adecuado.

41 Platt, Simon: "Organs of the vice-regal period in four mexican cathedrals", en The Organ Yearbook, XII, 1981, p. 75. Este autor considera al órgano citado como anónimo, sus observaciones sobre las etiquetas con los nombres de los registros se pueden confrontar con la lista de los mismos en el documento de "Entrega del órgano grande" por parte de Félix Izaguirre, donde también aparecen los registros y mixturas de la cadereta, los del órgano chico, así como los registros y otros elementos que excedieron a los que habían sido originalmente contratados en 1707. ACCP, Música, Leg. de órganos [1660-1805], exp. del 26 de marzo de 1710, ff. 29r-30r. Asimismo compárense con el listado de registros que tiempo después realizó Manuel José Chacón para "la reforma al órgano grande", enviado al chantre de la catedral el 29 de mayo de 1797. Íbid., Leg. de órganos, exp. s.n. f.; Sobre la participación de Félix Izaguirre y su hermano Tiburcio Sanz en la instalación del gran órgano de la catedral de México construido en España por Jorge de Sesma al finalizar el siglo XviI, ver los artículos de PePE, Edward C. : "An organ by Jorge de Sesma for Mexico City Cathedral", en Revista de Musicología, 29/1 (2006), pp. 127-162; ID.: "The installation by Tiburcio Sanz and Félix de Yzaguirre of the Jorge de Sesma organ for Mexico City Cathedral: 1692-1695”, en Revista de Musicología, 29/2 (2006), pp. 433-479. Véase también GuZmán Bravo, José Antonio: "Documentos inéditos para la restauración de los órganos históricos de la catedral metropolitana de Nuestra Señora de la Asunción de México Tenodititlan (1688-1736)", en Anuario Musical, №. 62, (enero-diciembre 2007), pp. 125-170. Acerca de este artículo, cabe aclarar que el allí citado "Archivo Cervantes", en el que se sustenta buena parte de su documentación, en realidad corresponde a la Colección Enrique A. Cervantes, que pertenece y se encuentra a consulta en el Centro de Estudios de Historia de México Carso (Condumex). Al respecto podemos comentar que, desde nuestro punto de vista, resulta evidente que las fuentes utilizadas en tales artículos de los profesores PEPE y GuZMÁN BRAVO pueden ser en realidad complementarias; al revisarlas, confrontarlas y cruzarlas, tendríamos una visión más completa y objetiva, y se despejarían muchas dudas, confusiones e interpretaciones acerca de tan importante tema. 


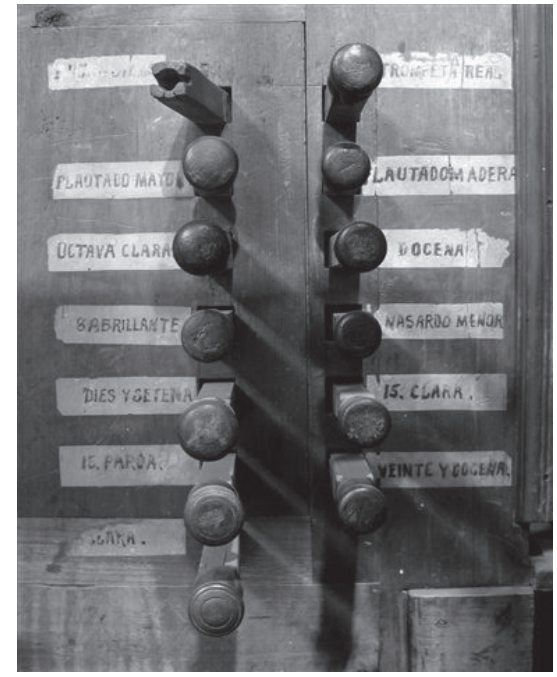

Fig. 3. Tiradores y etiquetas de los registros de mano izquierda.

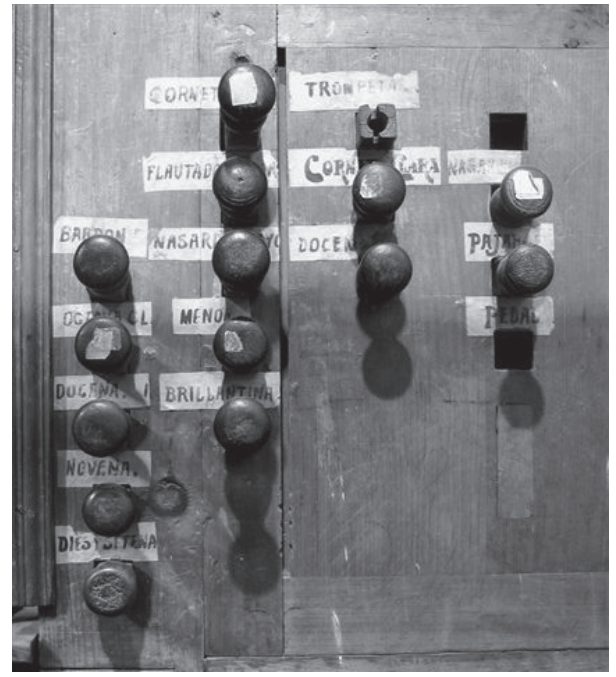

Fig. 4. Tiradores y etiquetas de los registros de mano derecha.

Cuadro de registros 1

\begin{tabular}{|c|c|c|c|}
\hline \multicolumn{2}{|c|}{$\begin{array}{c}\text { Manuel José Chacón, } 1789 \text { (Escritura de } \\
\text { obligación) }\end{array}$} & \multicolumn{2}{|c|}{ John Fesperman, 1980 (Estudio) } \\
\hline Mano izquierda & Mano derecha & [sic] & Treble \\
\hline $\begin{array}{l}1^{\circ} . \text { Flautado Mayor } \\
{\left[13 \text { palmos }\left(8^{\prime}\right)\right]}\end{array}$ & $\begin{array}{l}\text { 1. Flautado Mayor } \\
{\left[13 \text { palmos }\left(8^{\prime}\right)\right]}\end{array}$ & Bajoncillo (8' or $\left.4^{\prime}\right)$ & $\begin{array}{l}\text { Corneta Real (possibly } \\
\text { Trompeta) }\end{array}$ \\
\hline $\begin{array}{l}2^{a} \text {. Octava Clara } \\
{\left[61 / 2 \text { palmos }\left(4^{\prime}\right)\right]}\end{array}$ & $\begin{array}{l}\text { 2. Id. [Flautado] Bardón } \\
{\left[13 \text { palmos }\left(8^{\prime}\right)\right]}\end{array}$ & Trompeta Real ( 8') & Trompeta \\
\hline $\begin{array}{l}3^{\text {a. }} \text {. Docena Clara } \\
{\left[4 \text { palmos }\left(22 / 3^{\prime}\right)\right]}\end{array}$ & $\begin{array}{l}\text { 3. Octava Clara } \\
{\left[\begin{array}{ll}6 & 1 / 2 \text { palmos }(4 ')]\end{array}\right.}\end{array}$ & Flautado Mayor (8') & Flautado Mayor \\
\hline 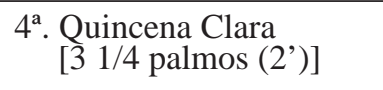 & $\begin{array}{l}\text { 4. Flauta Dulce } \\
{[2 \mathrm{~h}(\mathrm{II})]}\end{array}$ & Flautado Madera (8') & Corneta Clara \\
\hline $\begin{array}{l}\text { 5. Decisetena } \\
{\left[2 \quad 1 / 2 \text { palmos }\left(13 / 5^{\prime}\right)\right]}\end{array}$ & $\begin{array}{l}\text { 5. Docena. } \\
{\left[4 \text { palmos }\left(2 / 3^{\prime}\right)\right]}\end{array}$ & Octava Clara & Nasardo \\
\hline $\begin{array}{l}\text { 6. Decinovena } \\
{\left[2 \text { palmos }\left(1 / 3^{\prime}\right)\right]}\end{array}$ & $\begin{array}{l}\text { 6. Quincena. } \\
\text { [3 1/4 palmos (2')] }\end{array}$ & $\left(22 / 3^{\prime}\right)$ & Bardon \\
\hline $\begin{array}{l}\text { 7. Lleno de tres caños por } \\
\text { punto } \\
{[3 \mathrm{~h}(\mathrm{III})]}\end{array}$ & $\begin{array}{l}\text { 7. Decisetena } \\
{\left[2 \quad 1 / 2 \text { palmos }\left(13 / 5^{\prime}\right)\right]}\end{array}$ & Babrillante (Mixture ?) & Nasardo Mayor \\
\hline $\begin{array}{l}\text { 8. Nasardo Mayor } \\
{\left[4 \text { palmos }\left(22 / 3^{\prime}\right)\right]}\end{array}$ & $\begin{array}{l}\text { 8. Decinovena } \\
{\left[2 \text { palmos }\left(1 / 3^{\prime}\right)\right]}\end{array}$ & Nasardo Menor (4') & Docena \\
\hline
\end{tabular}




\begin{tabular}{|c|c|c|c|}
\hline $\begin{array}{l}\text { 9. Nasardo Menor } \\
{\left[21 / 2 \text { palmos }\left(13 / 5^{\prime}\right)\right]}\end{array}$ & $\begin{array}{l}\text { 9. Lleno de tres caños por } \\
\text { punto según arte } \\
{[3 \text { h (III) }]}\end{array}$ & Dies y Setena (1 3/5') & Octava Clara \\
\hline $\begin{array}{l}\text { 10. Nasardo Mediano } \\
{\left[31 / 4 \text { palmos }\left(2^{\prime}\right)\right]}\end{array}$ & $\begin{array}{l}\text { 10. Registro de trompetería } \\
{\left[13 \text { palmos }\left(8^{\prime}\right)\right]}\end{array}$ & 15. [Quincena] Clara (2') & Menor \\
\hline $\begin{array}{l}\text { 11. Registro de lengua } \\
{\left[61 / 2 \text { palmos }\left(4^{\prime}\right)\right]}\end{array}$ & $\begin{array}{l}\text { 11. Registro de trompetería } \\
{\left[13 \text { palmos }\left(8^{\prime}\right)\right]}\end{array}$ & 15. [Quincena] Parda (2') & $\left(22 / 3^{\prime}\right)$ \\
\hline $\begin{array}{l}\text { 12. Registro de lengua } \\
{\left[13 \text { palmos }\left(8^{\prime}\right)\right]}\end{array}$ & $\begin{array}{l}\text { 12. Corneta Clara de cinco } \\
\text { caños según arte } \\
{[5 \text { h (V)] }}\end{array}$ & Veinte y Docena (1') & Brillantina (Mixture ?) \\
\hline \multirow{5}{*}{$\begin{array}{l}\text { 13. Un Flautado de madera } \\
\text { pardo } \\
\left.\text { [13 palmos }\left(8^{\prime}\right)\right]\end{array}$} & $\begin{array}{l}\text { 13. Corneta de Ecos. } \\
{[5 \mathrm{~h}(\mathrm{~V})]}\end{array}$ & ....... Clara $\quad\left(11 / 3^{\prime}\right)$ & $\left(11 / 3^{\prime}\right)$ \\
\hline & $\begin{array}{l}\text { 14. Nasardo Mayor } \\
{\left[4 \text { palmos }\left(22 / 3^{\prime}\right)\right]}\end{array}$ & & Dies y Setena $\left(13 / 5^{\prime}\right)$ \\
\hline & $\begin{array}{l}\text { 15. Nasardo Menor } \\
{\left[21 / 2 \text { palmos }\left(13 / 5^{\prime}\right)\right]}\end{array}$ & & Corneta de Ecos \\
\hline & $\begin{array}{l}\text { 16. Nasardo Mediano. } \\
\text { [3 1/4 palmos (2')] }\end{array}$ & & $\begin{array}{l}\text { Pedal } \\
\text { knob) }\end{array}$ (label but no \\
\hline & & \multicolumn{2}{|l|}{ Tambor, Pájaros } \\
\hline
\end{tabular}

\section{Cuadro de registros 2}

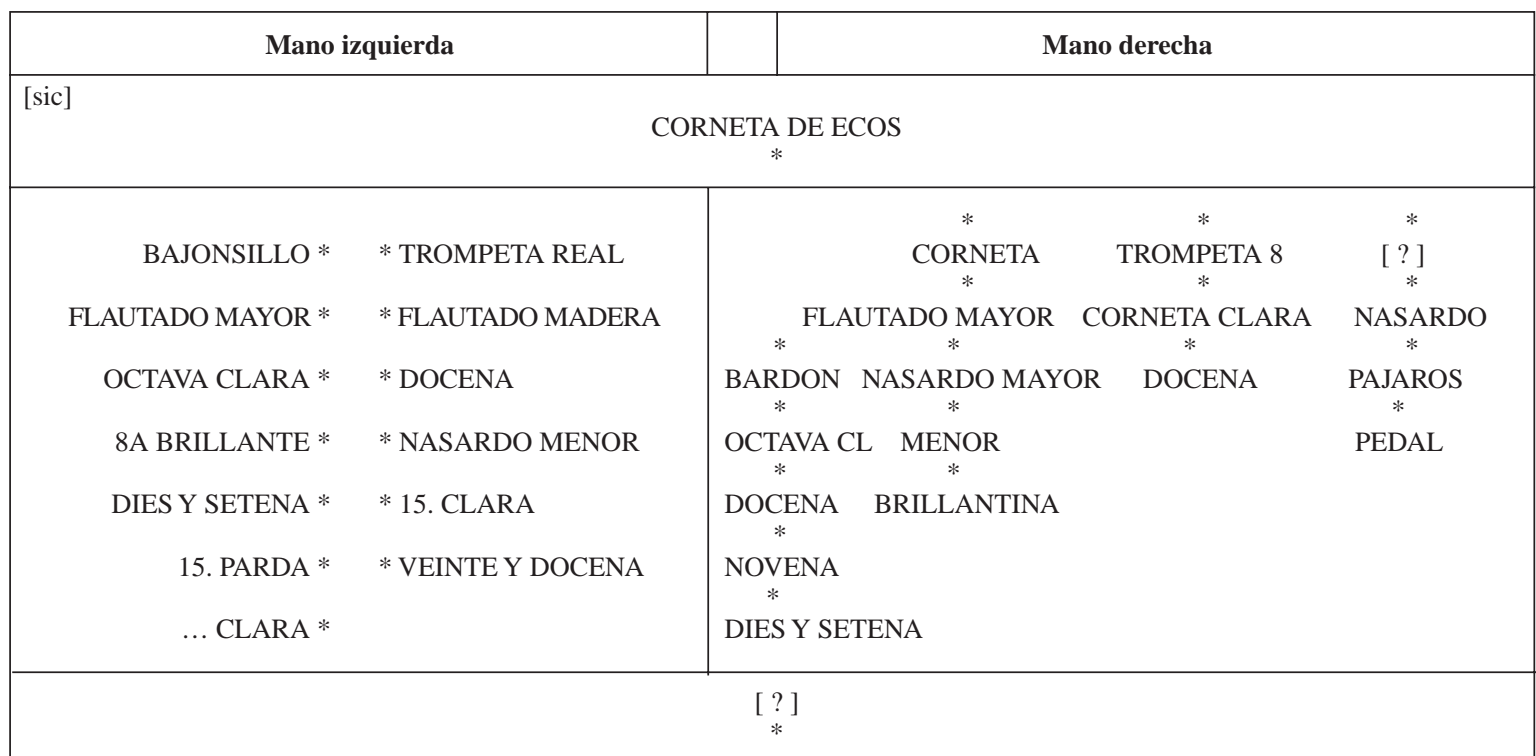




\section{Cuadro de registros 3.}

\begin{tabular}{|c|c|c|c|c|c|}
\hline \multicolumn{2}{|c|}{ Mano izquierda } & \multicolumn{4}{|c|}{ Mano derecha } \\
\hline \multicolumn{6}{|c|}{$\begin{array}{c}{[?]} \\
*\end{array}$} \\
\hline $\begin{array}{r}\text { Registro de lengua * } \\
\text { [Bajoncillo] } \\
\text { Flautado Mayor * } \\
\text { Octava Clara * } \\
\text { Lleno * } \\
\text { Decisetena * } \\
\text { Nasardo Mediano * } \\
\text { Decinovena * }\end{array}$ & $\begin{array}{l}* \text { Registro de lengua } \\
\text { [Trompeta Real] } \\
\text { * Flautado de madera } \\
\text { pardo } \\
* \text { Docena Clara } \\
* \text { Nasardo Menor } \\
* \text { Quincena Clara } \\
* \text { Nasardo Mayor }\end{array}$ & $\begin{array}{c}{ }^{*} \\
\text { Flautado Bardón } \\
* \\
\text { Octava Clara } \\
* \\
\text { Docena } \\
* \\
\text { Decinovena } \\
* \\
\text { Decisetena }\end{array}$ & $\begin{array}{c}* \\
\text { Corneta de ecos } \\
\text { * } \\
\text { Flautado Mayor } \\
* \\
\text { Nasardo Mayor } \\
* \\
\text { Nasardo Menor } \\
* \\
\text { Lleno }\end{array}$ & $\begin{array}{c}* \\
\text { Registro de } \\
\text { trompetería } \\
\text { [Trompeta Real] } \\
* \\
\text { Corneta Clara } \\
* \\
\text { Quincena }\end{array}$ & $\begin{array}{c}* \\
\text { Registro de } \\
\text { trompetería } \\
\text { [Clarín] } \\
* \\
\text { Nasardo Mediano } \\
* \\
{[?]} \\
* \\
\text { Flauta Dulce }\end{array}$ \\
\hline & & $\begin{array}{c}* \\
{[?]}\end{array}$ & & & \\
\hline
\end{tabular}

La escritura de obligación para la fabricación del órgano da cuenta del interés y necesidad que tenían los padres licenciado don Pedro Manuel de Olañeta, cura vicario y juez eclesiástico de la doctrina de Atlixco, y el doctor don Agustín de Souza, cura por su majestad de esta feligresía, de hacer construir un órgano nuevo para la iglesia parroquial de la villa de Atlixco, concertando la obra con José Manuel Chacón debido a su prestigio "como facultativo que es en la materia, y que ha acreditado con las obras de este género que hay en la ciudad de Puebla y en otras partes del reino", además de que ya ostentaba, como sabemos, el cargo de afinador en la catedral, lo cual también debió contribuir para promover su trabajo entre las parroquias de otros lugares; el costo de la obra acordado era de 4,000 pesos de oro común mas "el órgano que actualmente sirve en dicha iglesia" parroquial. Para la fecha del contrato ya se había librado como adelanto la cantidad de 2,000 pesos que fueron costeados por la "generosa magnanimidad" de un hombre muy próspero vecino de la villa, el presbítero licenciado don José Antonio de Garfias, quien fungía como abogado de la Real Audiencia, comisario del Santo Tribunal de la Fe, y además era labrador en el valle y propietario de varias fincas, haciendas y ranchos ${ }^{42}$. Sobre la

42 Entre las propiedades de este importante personaje en Atlixco en la década de 1790, se encontraban las haciendas y ranchos: San Juan Bautista Xonacatepec, Chilhuacán, Xalpatlaco, San Miguel Acocotla, Acatzingo, Tizayucan (o Tezayuca) y Cantarranas, inclusive un canal de aguas de riego de la región llegó a ser conocido como "Acequia de Garfias". Una relación de las 
generosidad del licenciado Garfias, hemos de recordar que Ignacio Maneyro ya nos informaba en 1792 acerca de la "suntuosa lámpara y arañas de plata, que la piedad y cristianos sentimientos del licenciado don José Garfias, presbítero avecindado en esta villa, [...] con otros costosos adornos dignos de su bizarría, ha cedido en obsequio y gratitud de la religión que abrazó en su pila bautismal" ${ }^{43}$, entre esos bienes, como hemos anotado, también podemos considerar - aunque no se mencione explícitamenteal órgano de Chacón. Por su parte los curas aportarían de la fábrica espiritual de la parroquia los 2,000 pesos restantes, de ellos 1,500 debían ser pagados en el mes de octubre, y 500 al entregar la obra, lo cual pedía la escritura se realizara a más tardar el mes de junio del año siguiente de 1790, seguramente para que estuviera terminado sin retrasos para la fiesta de la parroquia el 8 de septiembre. Los curas se obligaban también a cubrir la alimentación del maestro durante el tiempo que durara en ser armado el órgano, así como a costear los gastos del transporte de sus componentes desde Puebla, ya que tenía, según la misma escritura, avanzada su construcción.

En el proyecto anexo que la escritura dice ser un "apunte simple firmado por los otorgantes que ha de agregarse a este registro", se dan las medidas aproximadas de la caja del órgano: de 8 a 9 varas de altura por $51 / 2$ varas de frente (es decir $6.68 \mathrm{~m}$ a $7.52 \mathrm{~m}$ por $4.59 \mathrm{~m}$ ) ${ }^{44}$, las cuales resultan muy cercanas a las medidas reales de la altura y frente de la caja incluyendo las cornisas laterales; por otro lado el fondo de la caja que mide $1.65 \mathrm{~m}$, casi dos varas, corresponde a la medida de los costados que fue calculada por el maestro organero "con su fondo correspondiente al número de mixturas que sigue en que estribarán en su respectivo secreto", es decir por el tamaño del secreto, el cual apunta, será construido "de buen cedro y bien acondicionado", agregando que "la expresada altura [de la caja] es inclusive la talla u ornato", es decir incluyendo a los ornamentos calados que rematan a cada uno de los 7 "castillejos volados", cuya parte superior sirve de peana a igual número de esculturas policromadas de figuras femeninas que portan sendas cornucopias y de cuyos pabellones emergen flores y frutos, una octava escultura representa a una niña pequeña que también lleva su cornucopia y se encuentra sentada en el castillo central de la cadereta ornamental. A continuación del listado de registros o mixturas, avisa que todas estas familias de tubos se encuentran "bajo el sistema de 58 teclas, el que comienza desde el signo de Gsolrreut [Gesolreut], que es una $4^{\mathrm{a}}$ abajo del sistema conocido y regular en todo órgano [es decir en Cesolfaut], circunstancia de las más apreciables que pueda tener el expresado instrumento", este órgano tiene un manual partido o de medio registro y aunque su teclas y tal vez la reducción no son originales, conservó el número de 58 y su extensión (Sol2-Mi7), lo cual para su época y contexto resultaba verdaderamente excepcional. Al final el protocolo hace referencia a las aleaciones de los tubos en términos de "la finura del metal" de que están hechos, lo que podemos interpretar como de una mucho mayor proporción de estaño por sobre la de plomo, en relación a

haciendas y ranchos, así como de sus propietarios en la Villa de Atlixco de esta época, se puede consultar en ACcP, Papeles varios, L. 8, f. s.n.

43 Vid. supra nota 12.

44 Tomamos la medida de la Vara Castellana con su equivalencia a $83.59 \mathrm{~cm}$. 
la usanza convencional ${ }^{45}$, no así, desde luego, para los tubos de Nasardos y Corneta por razones de color del sonido. El constructor concluye — apegado a la teoría — que el órgano será "animado con el viento de tres fuelles de marca, con sus correspondientes tamaños" los cuales seguramente eran de tipo abanico con palanca, proporcionales a la dimensión de este tipo de instrumentos de 13 palmos ${ }^{46}$, para hacernos una idea, podemos citar a fray Pablo Nassarre quien informa puntualmente que los fuelles para este tipo de órganos deben ser de "diez palmos de largo y cinco de ancho, debe tener un geme con poca diferencia cada ángulo de la estancia abierta, en la suposición que ha de ser en cuadro", el contrapeso de cada fuelle de dichas proporciones debería ser "lo bastante el de poco más de dos arrobas", asimismo el conducto o portavientos que lleva el aire al secreto "en la suposición de que ha de ser cuadrado, basta que tenga cada uno un geme de ancho"47.

En términos generales podemos considerar que para la iglesia de Atlixco fue fabricado un órgano de 13 palmos ( $8^{\prime}$ ), de un teclado manual y de medianas proporciones, del orden que fray Pablo Nassarre denominaba "de segunda especie" ${ }^{48}$, cuya columna armónica y tímbrica está estructurada a partir de grupos básicos de registros y sus consonancias, que le confieren una disposición y tamaño más o menos convencional para los usos y necesidades litúrgico-musicales de un templo parroquial, cuyas dimensiones arquitectónicas rebasan el común de las iglesias del antiguo obispado de Puebla, no obstante, dicho instrumento era poseedor de notables características de ingeniería constructiva, propias de la organería desarrollada por Manuel José Chacón, que le daban una muy buena capacidad sonora y una particular, económica e inteligente combinación de registros partidos y medios registros que tenían, desde luego, sus antecedentes en un diseño usado y probado mucho tiempo atrás por la organería española, cuestión que fray Pablo Nasarre, por ejemplo, describía en estos términos:

45 Sobre este punto, por ejemplo, el tratadista Fernando A. de Madrid recomienda que "Toda la cañonería que ha de colocarse en la fachada, sería mejor hacerla de estaño fino sin mezcla alguna de plomo, pero podrá quedar buena aunque se ligue una quinta parte de plomo, y para todo lo demás de lo interior bastará ligar tres partes de estaño con una de plomo; y cuando mucho se quiera economizar se ligará un tercio de plomo con dos de estaño [...]. Algunos acostumbran ligar mayor porción de plomo para los pies de los flautados llenos \&c. y aunque esto sea disimulable en la cañutería menuda, no lo es en lo caños grandes porque la blandura del mucho plomo no puede resistir el crecido peso de flautas grandes; se hunden los pies, y por consiguiente se inutilizan estos caños muy en breve, o a lo menos pierden mucha parte de su voz y harmonía". Vid., MADrid, Fernando Antonio de: Cartas instructivas sobre los órganos. Documentos a los señores eclesiásticos que los costean y a los organistas que los revisan, usan y conservan... Jaén, Imprenta de Pedro de Doblaa, 1790, p. 13. Cabe comentar que una parte de las conclusiones de este autor está sustentada en un tratado francés que también fue conocido en la Nueva España, se trata de la obra de Bedos DE CelLes, François (о.s.в.): L'art du facteur d'orges... París, de l'imprimerie de L. F. Delatour, 1766-1770.

46 Ver doc. anexo núm. 6.

47 NASSARRe, Fray Pablo: Escuela música según la práctica moderna... [Zaragoza, Herederos de Diego de Larumbe, 1724]. Edición facsímil, Zaragoza, Institución "Fernando el Católico", 1980, t. I, p. 489, (las cursivas son del impreso). La arroba era una medida de peso y volumen, correspondiente a la cuarta parte del quintal, su equivalencia sería de unos $11.5 \mathrm{~kg}$. El geme era una medida de longitud, comprende la separación entre la punta del dedo pulgar y el índice formando un ángulo recto.

48 Íbid., pp. 481-482. Tomamos la antigua medida de longitud del palmo usual en Castilla equivalente a $20.89 \mathrm{~cm}$. Como es sabido la denominación del tamaño y proporciones del órgano "de segunda especie" se deduce por la longitud del tubo principal del Flautado Mayor de 13 palmos, equivalente a 8' (pies). 
"En los [órganos] que tienen el flautado de trece palmos, que son los que más común y ordinariamente se hallan, llevan después del flautado principal otro registro en octava, el cual está en proporción dupla, y tiene el caño mayor, como seis palmos y medio. Después se sigue otro registro en especie de docena, el cual está en proporción tripla con el flautado mayor, teniendo tres partes una. Después debe llevar otro registro en especie de cuadrupla, teniendo cuatro partes del flautado una, éste. Debe llevar otro después en especie de decinovena, la cual es de proporción séxdupla, teniendo de seis partes una del flautado. Después de estos registros se sigue el de lleno, que en unos órganos es de más número de caños, que en otros (y esto se ha de medir según la capacidad del templo), lo común es llevar cuatro, o cinco caños por punto. Si son cautro, poniendo el primero en especie de decinovena, puede haber dos en ventidocena, y uno en ventiseisena. Si fueren cinco, pueden ser la misma composición, añadiendo para el quinto la especie de ventinovena. También será buena composición, si los dos caños primeros estuvieren en ventidocena, y no habiendo de llevar mas que cuatro, el tercero en ventiseisena, y el cuato en ventinovena. Y si hubieren de ser cinco, se dobla la ventiseisena. Cualquiera de estas dos composiciones hace muy brillante y claro el lleno"49.

Efectivamente, conforme a la tradición y a la teoría, nuestro instrumento por su dimensión y proporciones tiene como base de sus registros el "Flautado Mayor" de 13 palmos u 8', registro fundamental y simple de mano izquierda y derecha con tubos de tipo labial; "correspondiente a éste [registro] seguirán las demás mixturas, según arte en lo interior de la caja”, es decir continuando dentro de los Flautados con el registro simple de "Octava Clara" que es otro registro natural o de consonancia perfecta de 6 1/2 palmos o 4' dispuesto a extensión completa, cuya tesitura de tenor se ubica a una octava diatónica sobre el Flautado de 13 ("en proporción dupla"). A éste sigue la "Docena Clara", registro de composición grave, de una hilera simple, cuya longitud mayor es de 4 palmos o 2 2/3', y su tesitura armoniza a una docena natural u octava y media sobre el Flautado de 13 ("en proporción tripla"); en el orden establecido, aparece otro registro de composición de una hilera simple que es el de Quincena del Flautado, en nuestro caso "Quincena Clara" de 3 1/4 palmos equivalente a 2' de longitud, con un intervalo de quincena diatónica y natural o dos octavas arriba del Flautado de 13 y correspondiente a 1/4 de longitud de éste ("en especie de cuádrupla, teniendo cuatro partes del flautado una"); le sigue la Decisetena del Flautado que Chacón denomina solamente "Decisetena", también de una hilera de tubos a partir del de 2 1/2 palmos o 13/5' pies en proporción al Flautado Mayor y con 17 puntos sobre éste, es también un registro simple y de composición con extensión de mano izquierda y derecha; concluye esta serie de hileras simples la "Decinovena" que es la más aguda de ellas y lleva también la extensión completa, su intervalo es de 19 puntos naturales sobre al Flautado de 13, a proporción

49 Íbid., pp. 482-483. 
de casi 2 palmos o 1 1/3' ("de proporción sexdupla, teniendo de seis partes una del flautado") ${ }^{50}$. Cabe añadir que el calificativo "Clara" en los primeros registros alude más bien a su timbre característico frente a sus antónimos de color de sonido más bien de tipo oscuro: "Parda", "Nasarda" o "Bastarda" que veremos más adelante.

En la disposición de las diferentes registros el maestro organero continúa su listado con uno de los más característicos del órgano que es el de Lleno de los flautados, al que agrega deberá ser un "Lleno de tres caños por punto según arte" en ambas manos, es decir de tres tubos por tecla o por nota, cumpliendo de esta manera con las recomendaciones teóricas, por otro lado el constructor no anota la especificación de sus tesituras ni la de sus reiteraciones o aumentaciones, sin embargo, la tesitura inicial de estos tubos en realidad es la que seguiría al último de los registros simples, por lo tanto en nuestro caso serían la Veintidosena de tesitura de 1', la Veintiseisena de 2/3' y la Veintinovena de 1/2', que conforman los armónicos 8, 12 y 16 de la serie del Flautado Mayor. No obstante tiempo atrás, el tratadista Nasarre señalaba acerca del Lleno "que es lo suficiente de tres caños por punto: uno en especie de decinovena, otro en veinteidosena, y otro en veintiseisena" ${ }^{1}$ aclarando que "estas especies se han de entender con el flautado de treze palmos, no con el que lleva de seis y medio dicho órgano". Se trata de un registro compuesto formado de varias hileras de tubos que en su función "deben ir en diferentes especies, y se reduce a compuestas de octavas y quintas, unas más remotas que otras" 52 .

Siguiendo con los registros partidos de ambas manos, Chacón propone en su proyecto incluir un mínimo grupo de Nasardos, cuya familia tímbrica (de tipo nasal, no brillante, y sin embargo muy sonora y acornetada), es la segunda en importancia en este tipo de órganos, esta especie de mixtura era también denominada "bastarda" y de ella Nasarre también recomienda que "conviene sea la mayor parte de plomo, porque el sonido sea oscuro [...] Semejante especie de cañutería fue práctica en los órganos para cornetas, y para los registros llamados Nasardos, y también para los flautados tapados. Llegan al tono de otros caños, no obstante que son más cortos, porque son más anchos, y todo lo que se les quita de longitud, se les da proporcionadamente a la latitud. [...] debe ponerse la latitud de esta especie de cañutería en proporción sexquiáltera, con la latitud de la otra, como dividiendo en dos partes la anchura de la cañutería clara, dar tres a la de esta especie que llaman Bastarda, que lo corto o lo largo del caño, lo dirá el tono en que hubiere de estar." 53 Se trata en el caso del órgano de Atlixco de tres tesituras de tubos de diapasón ancho de la familia de Nasardos simples de una fila y extensión completa, que el maestro organero tomó como modelo - en su denominación y tal vez en su forma constructiva y sistema acústico - del "órgano grande" de Felix Izaguirre de la catedral de Puebla, asimismo cabe comentar que el orden que asigna a estos Nasardos aparece de igual forma en un listado de los registros de dicho órgano, que como hemos visto Chacón mismo elaboró en 1797.

50 Íbid., p. 483.

51 Idem.

52 Íbid., p. 499.

53 Íbid., p. 486. 
De esta familia dispone un "Nasardo Mayor" que en realidad es una Docena Nasarda (o Docena Parda según el órgano de Izaguirre) cuya entonación corresponde a 4 palmos o 2 2/3' sobre el Flautado Mayor; un "Nasardo Menor" usualmente conocido como Decisetena Nasarda (o Decisetena Parda) de 2 1/2 palmos o 13/5'; y un "Nasardo Mediano" que corresponde a la Quincena Nasarda (o Quincena Parda) de 3 1/4 palmos o 2', completándose así el tercero, quinto y cuarto armónico respectivamente del registro de Nasardos.

En cuanto a los registros externos de lengüeta conocidos como "lengüetería tendida" o "trompetería de batalla" nuestro organero propone ciertas familias que aparentan ser de medio registro en su denominación, mismas que como veremos tienen una correspondencia y/o continuidad tímbrica en ambas manos, el artífice las enlista genéricamente como "dos registros de lengua" para la mano izquierda y "dos registros de trompetería" para la mano derecha, con lo que tendríamos en la fachada un mínimo Lleno de lengüetería horizontal de pabellón largo de tipo cónico o abocinado, colocado a dos filas superpuestas con sus tabloncillos acanalados a la altura del secreto. Si recurrimos nuevamente a Nassarre para conocer algunas de sus características y proporciones de mensuración y longitud, vemos que "Practicase también en los órganos otra cañutería que llaman de lengua de que se fabrican distintos registros, es de forma piramidal y rotunda. [...] El registro de Clarín (que ordinariamente es de la mitad del órgano arriba) practican mucho en ponerlo en proporción dupla, dándole doblado de largo, de lo que tiene la extremidad de ancho, y hace muy buen efecto cuando está en esta proporción. Si se pone en proporción tripla, imitan más al Clarín de Campaña en la voz, pero es menos. Las Trompetas Reales, el común diapasón de ellas es el de la proporción dupla bipartiens quintas, que es de doce a cinco, dándole de cinco partes que tenga la extremidad de ancho, doce de largo. Aunque soy de dictamen que este diapasón sólo le debe observar de medio órgano abajo, porque sean más suaves y claros los baxos, pero de medio arriba, en proporción dupla, porque tengan mayor voz" ${ }^{54}$. En el órgano de Chacón el primer par de registros para el ámbito del bajo de mano izquierda, en realidad estaba formado por un Bajoncillo de tesitura o entonación de 6 1/2 palmos o 4', y una Trompeta Real de 13 palmos u 8', y para el tiple en la mano derecha por un Clarín de 13 palmos u 8' y una Trompeta Real también de 13 palmos. Con estas familias tenemos como resultado dos medios registros bajos y dos medios registros tiples, en cierta forma independientes y con diferentes tesituras, que fueron dispuestos para poder "tañer seguido" en forma de registros enteros o para "tañer partido" a manera de medios registros.

Hemos dejado para la última parte los medios registros que dispuso Chacón en la construcción de este órgano, en primer término tenemos el caso de un "Flautado de madera pardo" de entonación de 13 palmos en el bajo y un "Flautado Bardón" también de 13 para el tiple (registros que en un momento podrían tener cierta correspondencia tímbrica a manera de registro partido de extensión completa). Asimismo hemos observado en algunos órganos de la región — lo que puede ser un caso aislado— que

54 Íbid., pp. 486 y 487. 
el "Flautado Bardón" lleva en la mano izquierda caños de madera y en la derecha tubos metálicos de la familia del flautado tapado (en los que evidentemente se reduce a la mitad su longitud), por lo que podríamos asociarlos por su función y características tímbricas con los registros y tesituras del Flautado Bordón, o del Violón. Es probable que el término "Bardón" sea una denominación novohispana, en Puebla por lo menos, la primeras menciones que conocemos de este registro y su apelativo las realizó Felix Izaguirre en el contrato para la construcción del "órgano grande" de la catedral de Puebla en 1707, y en el citado memorial de entrega del mismo en 1710.

El constructor agrega una "Flauta Dulce" que es un medio registro tiple de mano derecha, y unísono del Flautado de 13, usualmente hecho de madera y a dos caños por punto o dos filas, que se acompañaría en el bajo por el anterior "Flautado de madera pardo", según Fernando A. de Madrid "La flauta dulce o travesera se tocará sola con el violón en la mano izquierda, porque si se tocase con otros registros, éstos cubrirían sus voces y no tendría lucimiento alguno" ${ }^{55}$.

Para concluir en la escritura de obligación nos resta la familia de las Cornetas que es una mixtura de tubos de labio. De estos registros Nassarre nos dice "Compónense las cornetas de flautado tapado (en unisunus del treze), de octava, docena, quincena y diecisetena, aunque dobles estas dos especies últimas en las cornetas, que se hacen de mucho cuerpo. [...] Pónense también en registros sueltos, y a parte cada especie de consonancia, según la voluntad de los fabricantes, son los de esta especie de más cuerpo el sonido, y más obscuro, siendo de todo esto la causa el ser la cañutería más dilatada." ${ }^{56}$ Por su parte el maestro Chacón proyectó dos medios registros tiples de corneta, adicionando un secretillo especial para las series de la "Corneta Clara de cinco caños según arte" y para el arca de la "Corneta de Ecos". En la primera de ellas dispuso — tal como lo comentaba Nassarre — cinco hileras, a tesitura de 8' para el unísono con el Flautado Mayor, 4' para la octava, 22/3' para la docena, 2' a la quincena, y $13 / 5$ ' para la decisetena, completando una serie de 5 armónicos; como podemos apreciar no lleva una sexta fila, cuya decinovena también era común en los órganos españoles de su época, sin embargo, podemos observar que en la organería francesa, por ejemplo, seguían siendo muy usuales las cinco filas de corneta como lo indica el maestro benedictino Bedos en su tratado ${ }^{57}$. Por otro lado estas consonancias tienen sus correspondientes en igual número de filas de la "Corneta de ecos" asentada en el interior de su arca, y tenía la función de generar un efecto de cercanía, alejamiento y distancia (elementos de contraste de los planos sonoros que la organería desde el siglo XVII ha considerado en términos de "eco, contraeco y suspensión"), para imitar, combinar o dialogar con la otra corneta, a través de un dispositivo de control mecánico que hacía abrir, graduar y/o cerrar la caja a gusto del organista, quien lo accionaba mediante una palanca, un tirador o una rodillera. En este caso el organista y teórico Nassarre también observa y recomienda que: "los registros de ecos [...] ordinariamente se elevan del secreto principal en secretillo

55 MADRID, Fernando Antonio de: Cartas instructivas..., op. cit., p. 107

56 Nassarre, Fray Pablo: Escuela música..., op. cit., p. 486.

57 Bedos de Celles, François (o.s.B.): L'art du facteur d'orges..., op. cit., p. 50. 
aparte, recibiendo el aire por los conductos, tantos como puntos lleva el registro. Hácese una arca toda cerrada, la cual incluye en sí toda la cañutería. Ésta se ha de hacer con arte, que imite en la forma al orden con que está encerrada la cañutería, tanto que tenga un palmo de altura su cóncavo, o poco menos más que los caños, y dilatada cuatro dedos más, para que estando cerrada no desafine los registros que están dentro. Se ha de disponer con tal arte, que con facilidad pueda el organista cerrarla y abrirla, para que se pueda imitar bien el $e c o$ "58.

En las últimas tres décadas ha cobrado un especial interés en el ámbito musical mexicano, entre algunos estudiosos académicos y por parte de un creciente número de restauradores, más o menos especializados, el registro, estudio, restauración y conservación de los viejos órganos tubulares que forman parte del patrimonio cultural de México, considerados como bienes muebles y cuya gran mayoría al localizarse dentro de inmuebles eclesiásticos en buena parte del territorio nacional, se constituyen asimismo como bienes federales. En los estados de Oaxaca, Puebla, y Tlaxcala, que cuentan en conjunto con un asombroso acervo de más de 400 instrumentos de los siglos XVII al XX, ya se han iniciado algunas acciones para su registro y conservación, entre ellas, los trabajos de restauración ha sido en cierta medida aislados y lamentablemente no siempre han alcanzado los resultados deseados, por lo que el tema de su protección y marco legal, deberá ser una de la prioridades para los interesados en estos bienes culturales, y desde luego, para las autoridades federales competentes ${ }^{59}$. Asimismo, resulta interesante observar que los órganos históricos mexicanos comienzan a ser estudiados desde diferentes enfoques, disciplinas e interdisciplinas: musicología, organología, historia del arte, conservación y restauración, historia de la ciencia y la tecnología, etc., lo cual, sin duda, se orientará a enriquecer todas las acciones que se emprendan en este campo, ayudará a tomar importantes decisiones durante las intervenciones por mínimas que éstas sean, y fortalecerá en general los conocimientos que sobre tales obras de ingeniería constructiva tenemos, toda vez que se lleve a cabo una adecuada divulgación de las investigaciones y restauraciones que se encuentren en curso o que hayan sido concluidas, con lo cual tendremos un conocimiento detallado del desarrollo de estos trabajos y, en términos sociales, permitirá poner en valor a estos bienes que forman parte un patrimonio musical compartido.

58 NASSARre, Fray Pablo: Escuela música..., op. cit., pp. 499 y 500.

59 Véase los acuerdos, conclusiones y propuestas de Protocolo Oaxaca 2001. Sumario de los principios para la conservación y restauración de órganos en Latinoamérica, así como Normas para la restauración de órganos históricos en México: Interpretación e implementación. Oaxaca, Instituto de Órganos Históricos de Oaxaca, A.c. (IOHIO), 2002. Sobre los últimos trabajos de registro e investigación en Oaxaca, ver Delgado Parra, Gustavo y x Gómez Castellanos, Gustavo: Organos históricos de Oaxaca: estudio y catalogación, México, Banamex, 1999 y WinTer, Cecilia: "Los órganos históricos de Oaxaca: una ventana al pasado", en Anuario Dominicano, t. II (2006), pp. 369-400. 


\section{Documentos ANEXos}

\section{Decreto para nombrar afinador de órganos de la catedral de Puebla a José Miguel Chacón (30 de mayo de 1776).}

[Encabezamiento:] Nos el Obispo, Deán y Cabildo de la Santa Iglesia Catedral de la Ciudad de la Puebla de los Ángeles.

[Al margen:] Constructor de órganos.

[Al centro:] Por cuanto se halla vacante el empleo de afinador de órganos de esta nuestra santa iglesia y conviniendo nombrar sujeto que lo sirva, en cabildo que celebramos con previa citación a los veinte y nueve días de este presente mes de mayo, nombramos a don José [Miguel] Chacón (maestro de fabricar órganos). Por tanto atendiendo a los méritos que concurren en dicho don José, a haberse examinado en otra ocasión y reedificado el órgano mediano, con que ha manifestado su idoneidad, lo relevamos del examen que se previene en el Edicto que libramos para proveer dicho empleo, y por el presente lo nombramos elegimos y señalamos por Afinador de los referidos órganos, para que, como tal los cuide y conserve ilesos, afinándolos todas las ocasiones que sea necesario, de modo que siempre estén en corriente para que el organista pueda tocar cualquier mixtura en las principales funciones y en los divinos oficios, siendo e su cargo hacer las composturas precisas, y que no excedan de diez pesos, y por el trabajo que impidiere le asignamos el salario que han gozado sus antecesores. Y mandamos sea el nominado don José [Miguel] Chacón tenido por tal Afinador de órganos de esta nuestra santa iglesia, y que se le guarden todos los honores que le tocan y pertenecen. Dado en nuestra sala capitular eclesiástica de la ciudad de la Puebla de los Ángeles, firmado por nos, sellado con el sello de nuestra secretaría, y refrendado por nuestro infrascripto secretario a treinta días del mes de mayo de mil setecientos y setenta y seis años.

El Obispo de la Puebla. [Rúbrica]

[Margen izquierdo:] Se tomó razón a la letra en el libro de decretos corriente a foja 22 y su vuelta, y 23. [Rúbrica]

[Rúbricas del cabildo]

[Al centro:] Por mandato de su señoría ilustrísima y el muy ilustre y venerable señor deán y cabildo.

Lic. Juan de Vargas, secretario. [Rúbrica] 
[Margen inferior:] Vuestra Señoría Ilustrísima nombra de afinador de órganos de esta santa iglesia a don José Chacón, maestro de fabricar órganos.

ACCP, Música, Leg. de órganos [1660-1805], exp. s.n.f.

\section{Noticias sobre el taller de organería de Manuel José Chacón, algunos detalles sobre la fabricación de órganos y otros instrumentos (12 de septiembre de 1786).}

Puebla y agosto 24 [de 1786].

Don Manuel Joseph Chacón Duarte y Dávila que vive en la calle nombrada de Cholula, casa número 24, profesor de música instrumental, afinador de los órganos de la santa iglesia catedral, ha inventado muchos y diversos modos de fabricar órganos, tanto en lo hermosos de su fachada, cuanto en lo esencial de su interior fábrica: bien entendido, que por muchos cuerpos que estos tengan, y extraordinaria colocación de su canutería [tubos o caños], no hará un solo caño o flauta que sea ociosa en el efecto del sonido: con lo que ese excusará en el defecto que dice haber notado en los mejores que hasta la presente se han construido; los cuales aunque a la vista se presentan hermosos por la bella simetría con la que están colocadas las flautas, muchas de ellas son absolutamente mudas por la incomodidad de los sitios en que están colocadas. Este defecto, asegura el mencionado, que no tendrán los que promete hacer; antes por el contrario, propone que su disposición sea tal, que por vestidas que sus plantas se dispongan, no habrá planta alguna que no suene.

Demás de lo referido, asegura; que sin faltar a las especies musicales con que en un órgano deben ir colocadas cuales quiera mixturas, según los establecido en el arte, hará hacer otros nuevos efectos a las flautas en lo extraño de sus ecos, claridad, viveza, y resonancia, tanta, que como mostrará el efecto, excedan a cuantos órganos se han oído hasta el día, y lo que es más, remedando perfectamente a todos los instrumentos de vientos, como fístulas militares, clarines, claritones, flautas dulces, octavinos, y cuantos hay conocidos hasta el día; como también la perfecta imitación de muchos de los de cuerdas, sin necesidad de ellas, pues todo se ha de verificar por medio sólo de las flautas. Para cumplimiento de todo lo dicho queda empeñado en ir dando noticia en las gazetas posteriores de cada cosa en particular de las propuestas, para que las personas de gusto logren el que les ha de causar la construcción de cualesquiera invención de las predichas, y las que se fueren publicando.

En la actual para dar principio a los prometido, a más de hacer saber que en la citada casa de su obrador se fabrican órganos de diversas especies, y cilindros de todos tamaños, no sólo para el fin de enseñar pájaros, sino para particulares diversiones de las casas, y estos con [p. 194] tocatas de mucho gusto a el uso y modo de la tierra: promete que en todo órgano de los que hiciere con el prospecto de excusar algún gasto les construirá con un cierto artificio, que quedará a el arbitrio del 
organista, cuyo uso se advertirá en caso que se formalice contrato de alguno de esta naturaleza, con el cual logrará sin quitarse de su común asiento, que le resulte un efecto tan maravillosos y extraño, que ponga en admiración a los más diestros facultativos, y es (sin embargo de haber dicho en todo órgano, pues en los grandes también lo hará) que en lo medianos, que son los más frecuentes, por ser mayor el número de iglesias chicas, los cuales como de reducidos tamaños son de limitadas mixturas, que por lo regular suelen ser ocho o diez, que hagan tal efecto con el antedicho artificio, cual lo harían siendo doble el número de mixturas: advirtiendo que aunque de lo dicho es fuerza deducir que el precio de dichos órganos halla de ser mayor, por el costo de este más agregado, nunca llegará a ascender a el que tendrían si el que es de ocho se pidiera de diez y seis, el de diez de veinte, etc.

De todo lo expuesto y de lo que promete el artífice en las siguientes, desde luego afianzará su ejecución con personas de distinción y de facultades de dicha ciudad.

Gaceta de México, martes 12 de septiembre de 1786, t. II, núm. 17, pp. 193 y 194.

\section{Noticias sobre diversos aspectos técnicos y constructivos de los órganos fabricados por Manuel José Chacón (21 de noviembre de 1786).}

Puebla y octubre 20 [de 1786].

Don Manuel Joseph Chacón Duarte [y Dávila], profesor de música instrumental, de quien se trató al principio de la Gazeta número 15 [núm. 17] cumpliendo con lo prometido en ella, dice pondrá en práctica cierto temple de órgano, que inventó en Valencia el célebre don Félix Falco, y ejecutó a satisfacción de los músicos de la capilla real a presencia del señor Carlos Segundo, que fue muy aplicado a esta parte de las matemáticas.

Hallarse en el expresado temple el círculo músico tan deseado, que consiste en que todas las octavas que se comprenden en el sistema estén con igual proporción: esto es, que aunque transporten una tocata por todas las cuerdas o teclas no sólo resulten las disonancias que se advierten entre los instrumentos y órganos; pero ni aún las que en el órgano resultan en el establecido temple. Supuesto lo dicho promete poner otro artificio de todo organista, con que resulte un efecto muy útil, y es que bajen dichos órganos instantáneamente medio, uno, tres o más puntos, sin que desmerezca su afinación: las comodidades que ofrece son muchas, y advierte, que aunque en todo órgano del temple corriente puede

aplicarse el invento; pero que no se conseguiría otra cosa, que el evitar a los organistas el transportar; y en el que promete no sólo se consigue esto, sino que baje o no baje el órgano, no halla las disonancias que frecuentemente se notan. 
Promete igualmente poner en todo órgano de los que nuevamente fabrique, un Violón y Contrabajo, sin dependencia de cuerda alguna, con tal naturaleza y perfección, que aún los inteligentes duden si lo son efectivamente.

De esto ya ha dado pruebas en el órgano que construyó para la iglesia de San Agustín [de Puebla en 1779], pero aún le faltan a éste muchos requisitos para su perfección, que de ningún modo omitirá siempre que se le mande hacer con dichas circunstancias.

Gaceta de México, martes 21 de noviembre de 1786, t. II, núm. 22, p. 241.

\section{Memorial de Manuel José Chacón solicitando la plaza interina de afinador de órganos de la catedral de Puebla (6 de febrero de 1789).}

[Al margen:] Sala capitular de esta santa iglesia y febrero 6/89.

Se concede al suplicante el ínterin que solicita de la plaza de afinador con las obligaciones y renta con que hasta el presente la ha servido, así lo acordaron los señores de este muy ilustre y venerable cabildo y lo firmó el señor deán.

Irigoyen. [Rúbrica]

Ante mí: Dr. Ignacio Landívar, secretario. [Rúbrica]

Tomada razón de este expediente a fojas 191 del libro de decretos de esta contaduría. Ángeles 14 de mayo de 1789. [Rúbrica]

[Al centro:] Ilustrísimo y Venerable Señor Deán y cabildo.

Manuel José Chacón Duarte [y] Dávila, constructor de órganos y vecino de esta ciudad. Como me halla lugar en derecho, hago las protestas legales necesarias. Ante vuestra señoría ilustrísima parezco y digo: que me hallo en la actualidad cuidando de los órganos de esta santa iglesia por fallecimiento de mi padre don José [Miguel] Chacón, quien sirvió la plaza de afinador de ellos desde el año pasado de setenta y cuatro [oficialmente desde 1776], que se dignó este venerable cabildo consignarle en dicha ocupación.

Ha sido bien notorio que desde su ingreso a ella, acompañé a dicho mi padre, solicitando siempre su puntual desempeño, sin darse exemplar que faltara yo a ir a la santa iglesia cuantas veces se deseaba a este trabajo y servicio, mayormente después de corridos algunos años de su nombramiento en la mencionada plaza, que naturalmente la edad le fue llenando de achaques y enfermedades, por lo que me era forzoso acompañarle, con este más poderoso motivo de no estar en disposición sus fuerzas de resistir el trabajo y fatigas que la ocupación apareja.

Ya se deja entender que habiendo corrido más tiempo y aumentándosele al referido mi padre sus accidentes, hasta llegar a no salir de casa mas de a el preciso cumplimiento de los cristianos preceptos, 
y esto arrimado a un báculo, era regular que la asistencia de dichos órganos la atendiera yo solo, como lo verifiqué hasta su fallecimiento.

Después de éste he continuado hasta el presente día con igual esmero y eficacia, haciendo en el relacionado servicio, el uso de mis deberes como ha sido constante en las funciones presentes que por razón del tiempo han ocurrido, en la que no he faltado a dar el acostumbrado lleno a la obligación.

Todo lo cual hago presente a la integridad de vuestra señoría ilustrísima para que elevándolo al grado de mérito, se digne su justificación consignarme en el ínterin de dicha plaza. Por tanto a vuestra señoría ilustrísima suplico se sirva decretar como pido, en que recibiré gracia y justicia.

Manuel José Chacón Duarte y Dávila. [Rúbrica]

ACCP, Música, Leg. de órganos [1660-1805], exp. s.n.f.

\section{Traslado del decreto para nombrar afinador de órganos de la catedral de Puebla a Manuel José Chacón (14 de mayo de 1789).}

Ha memorial presentado por don Manuel [José] Chacón pidiendo que por el fallecimiento de su padre don José [Miguel] Chacón, afinador de los órganos de esta santa iglesia, y alegando el servicio que ha hecho y está haciendo [f. 191r. Margen izquierdo: "Afinador de órgano interino Manuel Chacón”.] en dicha ocupación, se le concediese el ínterin de esta plaza. Se proveyó el decreto del tenor siguiente:

Sala capitular de esta santa iglesia y febrero 6 de 1789.

Se concede al suplicante el ínterin que solicita de la plaza de afinador con las obligaciones y renta que hasta el presente la ha servido. Así lo acordaron los señores de este muy ilustre y venerable cabildo y firmó el señor deán Irigoyen.

Ante mí: doctor Ignacio Zaldívar, secretario, cuyo expediente se devolvió al interesado en esta fecha que lo demostró.

Contaduría, Ángeles 14 de mayo de 1789.

Lagunas C. R. [Rúbrica]

ACCP, Libro núm. 2 de Decretos de cabildo [1775-1885], ff. 190v-191r. 


\section{Escritura de obligación para la construcción del órgano de la iglesia parroquial de la Villa de Atlixco (3 de agosto de 1789).}

[Margen izquierdo:] Obligación para la obra del órgano de la iglesia parroquial desta villa.

[Al centro:] En la Villa de Carrión, valle de Atlixco, a tres de agosto de mil setecientos ochenta y nueve años, ante mi el escribano y testigos, los señores licenciado don Pedro Manuel de Olañeta, cura vicario [continúa en f. 58r] foráneo y juez eclesiástico de esta doctrina, y doctor don Agustín de Sousa, cura asimismo, por su majestad, de esta feligresía, y don Manuel Chacón, vecino de la ciudad de Puebla, y residente en esta villa, a quien doy fe conozco con expresa renuncia que hacen de las leyes de la mancomunidad como en ellas se contienen, dixeron: que necesitando dichos señores curas de fabricar un nuevo órgano para su iglesia parroquial de esta Villa, lo concertaron con el otorgante, don Manuel, como facultativo que es en la materia, y que ha acreditado con las obras que de este género hay en la ciudad de Puebla y en otras partes del reino, y quedaron convenidos en que ha de fabricar el mencionado órgano, con las maderas, metal, mixturas, tamaño y circunstancias que constan en un apunte simple, firmado por los otorgantes, que ha de agregarse a este registro para que salga por principio de la copia, o copias que de este instrumento hallan de darse, y por la cantidad de cuatro mil pesos de oro común, y el órgano que actualmente sirve en dicha Iglesia. Y de la que ha percibido de presente una libranza de dos mil pesos que a favor del otorgante don Manuel, dio el presbítero licenciado don José Antonio de Garfias, abogado de la real audiencia, comisario del santo tribunal de la fe, vecino de esta villa, y labrador en su valle, y son los mismos con los que contribuye para dicha obra la generosa magnanimidad del predicho licenciado, un mil quinientos pesos, que los señores curas otorgantes han de darle en todo el mes de octubre de este año, y los quinientos restantes el día que dé entregado el órgano, y cuyas dos partidas le han de satisfacer los señores curas de las rentas de la fábrica de dicha iglesia, obligándose a su cumplimiento y [f. 58v.] a darle un cubierto en cualquiera de las mesas de dichos señores curas, todo el tiempo que durare en esta villa, para armar y concluir dicho órgano, el expresado don Manuel y a quien le han de costear el transporte de la obra desde la ciudad de la Puebla a esta villa, y en el coro de la iglesia de ella, ha de recibir el órgano viejo; y el nuevo ha de estar en alguna manera servible en todo el mes de junio del inmediato año venidero, o antes si le fuere posible, haciendo graciosamente los esfuerzos para verificarlo, pues gran parte de él tiene construida en el día. Y baxo cuyas condiciones, tiempo y cantidades se obligan mutuamente los otorgantes a darle el debido verificativo, confesando como confiesa el otorgante don Manuel, haber servido la libranza de dos mil pesos de que ha hecho mención, sobre que renuncia decir lo contrario, leyes de no entrego, y su prueba; y obligándose como se obliga, del cumplimiento de lo pactado y bienes, habidos y por haber, y los señores curas lo ejecutan con los bienes y rentas presentes y futuras de la ya citada fábrica; y los tres otorgantes dan poder a los jueces, justicias y prelados que de sus respectivas causas, conforme a derecho puedan conocer, renuncian su fuero, domicilio y vecindad, la ley sit convenerit, con las demás de su favor y defensa, y la general del derecho para que les compelan como por sentencia pasada es cosa juzgada. Así lo otorgaron y 
firmaron, siendo testigos: don Félix de Galvez y Boleaga, don Pedro José Jurado y don Jerónimo Anastasio Quintero, presentes y vecinos. Doy fe. Enumerado $=$ que $=$ vale $=$ testado $=\mathrm{ol}=$ no vale.

Pedro Manuel de Olañeta. [Rúbrica]

Don Agustín de Souza. [Rúbrica]

Manuel José Chacón. [Rúbrica]

Ante mí: José Ximénez Bilchiz, escibano real, público y de cabildo. [Rúbrica]

[f. 57r.]

[Anexo: "Apunte simple firmado por los otorgantes"]

[Al centro:] Tamaños del órgano son a saber:

Su altura de ocho a nueve varas poco más o menos.

Ancho de su frente en lo neto de la obra, son cinco y media varas, con su fondo correspondiente a el número de mixturas que sigue en que estribarán en su respectivo secreto de buen cedro, y bien acondicionado, siendo de advertir que en la expresada altura es inclusive la talla u ornato, como también en su fachada o frente de arriba será distribuida en siete castillejos volados, todos en cuya parte habrá de colocarse [los flautados de] la mano izquierda:

$1^{\circ}$. Flautado Mayor, y correspondiente a éste seguirán las demás mixturas, según arte en lo interior de la caja, y son sobre el referido Flautado Mayor su

$2^{\text {a }}$. Octava Clara.

$3^{\mathrm{a}}$. Docena Clara.

$4^{\mathrm{a}}$. Quincena Clara.

5. Decisetena.

6. Decinovena.

7. Lleno de tres caños por punto [por cada nota o tecla].

8. Nasardo Mayor.

9. Nasardo Menor.

10. Nasardo Mediano.

11 y 12 . Yten mas dos registros de lengua.

[Tachado:] 12. Mano Derecha

[Margen izquierdo:] Yten más en dicha mano.

13. Un Flautado de madera, pardo. 
Mano derecha:

1. Flauta Mayor.

2. Id. [Flautado] Bardón.

3. Octava Clara.

4. Flauta Dulce.

5. Docena.

6. Quincena.

7. Decisetena.

8. Decinovena.

9. Lleno de tres caños por punto según arte.

[10. y 11.] 2. dos registros de trompetería.

12. Corneta Clara de cinco caños según arte.

13. Corneta de ecos.

14. Nasardo Mayor.

15. Nasardo Menor.

16. Nasardo Mediano.

[f. 57v.]

Todas éstas mixturas bajo el sistema de 58 teclas, el que comienza desde el signo de Gsolrreut [Gesolreut], que es una $4^{\mathrm{a}}$ abajo del sistema conocido y regular en todo órgano, circunstancia de las más apreciables que pueda tener el expresado instrumento como lo es también la finura del metal, a esto se agrega, por supuesto, ser animado con el viento de tres fuelles de marca, con sus correspondientes tamaños, y demás circunstancias.

Pedro Manuel de Olañeta. [Rúbrica]

Lic. Agustín de Sousa. [Rúbrica]

Manuel José Chacón. [Rúbrica]

AGNEP, Notaría de Atlixco, Escribano José Jiménez Vilchis, Protocolos del año de 1789, ff. 56v-58r. 


\section{Recomendaciones de José Manuel Chacón para el cuidado y conservación de los órganos de la catedral de Puebla (s.a.).}

Acerca de órganos, reflexiones importantes y algunas notas no menos esenciales.

$1^{\mathrm{a}}$. Que los órganos deben tocarse con frecuencia, o por lo menos una semana uno y otra otro, en obvio del perjuicio que se les sigue, aunque por otra parte le resulte en que contrae el movimiento de los miembros de sus máquinas, pero éste es menos nocivo y por consiguiente más fácil de reparar. En esta parte hay mucho que decir lo que en caso necesario insinuaré pormenor.

$2^{\mathrm{a}}$. Que para un órgano de la magnitud y circunstancias del nuestro, consabido [es que] debe tener dos fuelles; las razones por que dejo para el tiempo necesario.

$3^{\mathrm{a}}$. Que las ventanas que caen sobre los órganos deben ser tecalis [un tipo de alabastro de la región] en lugar de vidrios: el porqué, se deja ver, que es el riesgo de el agua, con el accidente que no es ajeno de suceder quebrándose la vidriera, y por consiguiente [se recomienda] echar tecali o cortina a las ventanas por donde dan los rayos del sol, el por qué, en caso necesario lo haré ver con física demostración.

$4^{\mathrm{a}}$. Que indispensablemente deben desempolvarse los órganos por o menos una vez en el año, apeando mucha parte de su cañutería [conjunto de caños o tubos], cuando no toda, cuya operación requiere que sea cuando el facultativo [el afinador] halle por conveniente.

$5^{\text {a }}$ Que quede de tal manera dispuesto el tránsito para los órganos, que sólo los organistas y fuellero puedan entrar con su llave determinada sólo para ellos, y lo mismo el afinador. Esta es una de las causas que a los órganos ha traído mucho daño, y por consiguiente a mí. En este punto hay mucho qué decir en las conjeturas que siempre se me han rodado, pero fundadas.

$6^{\mathrm{a}}$. Que muchas ocasiones, o por lo menos algunas, no se debe templar el órgano aunque esté destemplado, pues sabemos que no es conveniente en todo tiempo recetarle al enfermo porque el no curarlo a veces le es medicina, al caso viene la propiedad; pero sin embargo en lo que es trompeterías, pocas veces debe omitirse el no templarlas. Esto no me lo han dado los libros específicamente, pero sí para probarlo traen de donde deducirlo, mis observaciones y la experiencia han sido los maestros que me ministran estas reglas, las que físicamente pondré a la vista siempre que se ofrezca la resulta que trae.

Prescindo de otras muchas, como también de las notas que prevengo en obvio de la difusión.

$$
\text { ACCP, Música, Leg. de órganos [1660-1805], exp. s.n.f. }
$$


8. Memorial de José Antonio Chacón Rojano solicitando la plaza de afinador de órganos de la catedral de Puebla (suscrito después del 23 de abril de 1803).

[Encabezamiento:] Ilustrísimo y venerable señor deán y cabildo.

[Al centro:] Don José Antonio Chacón Roxano vecino de esta ciudad, ante vuestra señoría ilustrísima, ante el mayor rendimiento que puedo y debo, comparezco y digo que habiendo servido mi abuelo don José Miguel Chacón la plaza de afinador trece años y mi padre don Manuel [José] Chacón catorce años, y yo en compañía de mi padre once años, y al mismo tiempo por fallecimiento de mi padre he afinado en algunos conventos y he hecho algunas obras ocultas, y en la actualidad estoy concluyendo una de mediano porte, y juntamente por enfermedad de mi padre he afinado en lagunas ocasiones en esta santa iglesia. Por tanto, suplico rendidamente se me atienda con nombrarme para la plaza de afinador, pues me hallo demasiadamente pobre y cargado de familia, sin más amparo que el de Dios, y así pido rendidamente se me atienda a esta mi súplica, en que recibiré merced de su benignidad y grandeza.

A vuestra señoría suplico se sirva decretar como pido en que recibiré gracia y favor.

José Antonio Chacón Roxano. [Rúbrica]

ACCP, Música, Leg. de órganos [1660-1805], (memorial suscrito después del 23 de abril de 1803), exp. s.n.f.

Recibido: $7 / 10 / 08$

Aceptado: 20/10/08 